\title{
Social Presence: Conceptualization and Measurement
}

\author{
Karel Kreijns ${ }^{1}$ (D) $\cdot$ Kate Xu ${ }^{1} \cdot$ Joshua Weidlich $^{2}$
}

Accepted: 1 June 2021 / Published online: 22 June 2021

(C) The Author(s) 2021

\begin{abstract}
Social presence is an important construct in online group learning. It influences the way how social interaction unfolds online and affects learning and social outcomes. However, what precisely social presence is has been under debate, as presently a plethora of different definitions and measures exist preventing the development of a coherent research field regarding social presence and its defining role in online group learning. To solve the issue, we went back to the original social presence theory as devised by the communication researchers Short et al. (1976) to show that although they had a clear idea of social presence - namely "realness" of other persons in the interaction-their definition is ambiguous, not operationalizable, and the measurement of it questionable. We, therefore, disentangled their social presence theory and (1) reformulated the social presence definition to enable an operationalization in line with the previous conceptualization of social presence; (2) departed from the technological determinism of social presence; and (3) identified two other constructs closely linked to social presence, namely, sociability (as a medium attribute) and social space (as a group attribute). By reformulating the definition of social presence and by linking it to social space and sociability, we hope to contribute to a more coherent line of social presence research and to better understand interpersonal communication, group learning, and group dynamics when learning and working together in an online setting.
\end{abstract}

Keywords Social presence definition $\cdot$ Social presence measurement $\cdot$ Social space $\cdot$ Sociability

Karel Kreijns

karel.kreijns@ou.nl

1 Faculty of Educational Sciences, Open Universiteit, Valkenburgerweg 177, 6419 Heerlen, AT, Netherlands

2 Educational Technologies, DIPF | Leibniz Institute for Research and Information in Education, Rostocker Straße 6, 60323 Frankfurt am Main, Germany 


\section{Introduction}

Quite a number of educational researchers investigating online distance education consider social presence an important construct in online group learning (OGL). Group learning refers to the "instructional use of small groups so that students work together to maximize their own and each other's learning" (Johnson et al., 2014, p. 87). It is "an activity encouraging knowledge construction through mechanisms such as belief revision, conceptual change, externalizing knowledge and opinions, self-explanations, co-construction of knowledge and reflection" (Veerman, 2000, p. 68). In group learning, success is achieved only when other group members are also successful. Research on face-to-face group learning has shown numerous advantages of group learning over competitive (success is only achieved if others fail) or individual learning (success is achieved independent of others). A meta-study of 685 separate studies conducted by Johnson and Johnson (2014) confirmed that working together to achieve common group goals led to more higher-level reasoning, more frequent generation of new ideas and solutions (i.e., process gain), and transfer from group performance to individual performance (i.e., group-to-individual transfer). Hence, the growing interest in group learning and the application of it in online settings as well in order to create online group learning (Kreijns et al., 2021).

Social presence is associated with the use of computer-mediated communication (CMC) tools and electronic platforms for OGL in terms of the degree to which these CMC tools and electronic platforms can transfer the same face-to-face interpersonal communication, group learning, and group dynamics when learning and working together in an online setting. Social presence influences the way how the social interaction in OGL groups unfolds online, which, in turn, affects the learning outcomes (Tu and McIsaac, 2002; Zhao et al., 2014). Indeed, research has found social presence impacts group learning and group dynamics via social interaction (Tu, 2000) and vice versa; social interaction may reinforce social presence (Song and Yuan, 2015). Furthermore, Poth (2018) stated: "[d]etermining how to develop an individual's 'social presence' within the learning environment is key to promoting a more engaging and supportive educational experience, in which students become more motivated and can attain more success" (p. 89) and Mykota (2017) appraised social presence as "the critical affective component and [...] one of the more important constructs in determining the level of interaction and effectiveness of learning in an online environment" (p. 137).

However, despite its importance, a precise definition of social presence has been under debate as presently a plethora of different definitions of social presence and incompatible measures for assessing it exist (Lowenthal and Snelson, 2017). This resulted in a situation that brings much confusion because definitions of social presence may differ so much that they seem to stem from totally different frameworks or theories. The lack of a precise definition and incompatible measures prevents the development of a coherent research field regarding social presence, its determinants and consequences, and its defining role in online group learning. This explains why social presence researchers have found equivocal results. For example, Giesbers et al. (2014) found no difference in social presence experiences when text-based CMC was compared to web-based video conferencing, whereas this difference was expected (Sallnäs, 2005). They also did not find that web-based video conferencing led to improved student performance and higher student learning experiences; in fact, student performance was worse, which contrasts with other research findings (e.g., Satar, 2013).

In this paper, we present our solution to resolve this undesired and complex situation. To that end, we went back to the original social presence theory as devised by the communication 
researchers Short et al. (1976) to show that although they themselves had a clear idea of social presence - namely "realness" of other persons in the interaction - their definition is nonetheless ambiguous and not operationalizable. Further, their measurement of social presence is questionable for two reasons: (1) there was no construct validation of the measurement instrument, and (2) the measurement instrument did not assess the degree of perceived "realness" of other persons but rather persons' attitude toward a communication medium.

We, therefore, disentangled their social presence theory and (1) reformulated their social presence definition to enable an operationalization in line with their conceptualization of social presence; (2) departed from their technological determinism of social presence; (3) identified two other constructs, namely, sociability and social space. With respect to the first point, we reformulated social presence as the psychological phenomenon in which, to a certain extent, the other persons are perceived as physical "real" persons in technology-mediated communication enabled by CMC tools and electronic platforms (see also Kreijns et al., 2014; Weidlich and Bastiaens, 2017, 2019). With respect to the second point, Short et al. (1976) saw the physical attributes of the communication media completely determining the degree of social presence. As this technology determinism is nowadays much and rightly criticized (e.g., Gunawardena, 1995; Walther, 1993), we, therefore, propose "realness" of the other persons to be also determined by other factors as well. With respect to the third and last point, we define sociability as the capacity of CMC tools and electronic platforms to allow for the expression of social presence and the experience of it as well as for the emergence of a social space. As sociability is a capacity of CMC tools and electronic platforms, it is a medium attribute (Kreijns et al., 2002; Weidlich and Bastiaens, 2019). Social space is defined as the network of interpersonal relationships embedded in group structures of norms and values, rules and roles, and beliefs and ideals; a sound social space is manifested by sense of community, group climate, mutual trust, social identity, and group cohesion. These interpersonal relationships may exist in any group, for example, between the members of an OGL group or between participants in a learning network. Hence, social space is a group attribute (Kreijns et al., 2004). The three constructs, social presence, sociability, and social space, are interrelated with each other as they do not work in isolation: together, they influence how social interaction in groups is established and maintained. Figure 1 visually shows this as a triangle where the sides represent the interrelations and the vertices the constructs social presence, sociability, and social space; social interaction is positioned in the center of the triangle to reflect that it is affected by those three constructs. However, most social presence researchers - unwitting of the sociability and social space constructs - apply social presence theory wherein, in fact, the three constructs are collapsed into one "social presence" construct, causing a jingle-fallacy. This fallacy looms when two or more conceptually different constructs are erroneously assumed to be the same because they bear the same label. This jingle-fallacy explains the confounding situation.

This paper is outlined as follows: we start with the adoption of the original social presence theory by online distance educators to understand the interpersonal communication, group learning, and group dynamics in OGL groups and how this, in turn, affects learning outcomes (the "Social Presence and Online Group Learning" section). We continue by giving an overview of the many definitions and measures of social presence; the most frequently used social presence definitions and measures are elaborated. We point out that all these definitions and measures, however, created an undesirable confounding situation ("The Confounding Situation" section). We then noted that the confounding situation convinced some social presence researchers to "kill" social presence (the "How Further with the Confounding 
Fig. 1 The social presence, sociability, and social space triangle sociability:

focus on the capacity of CMC-tools and electronic platforms to allow for 1) the expression of social presence and the experience of it, and 2) the emergence of a social space

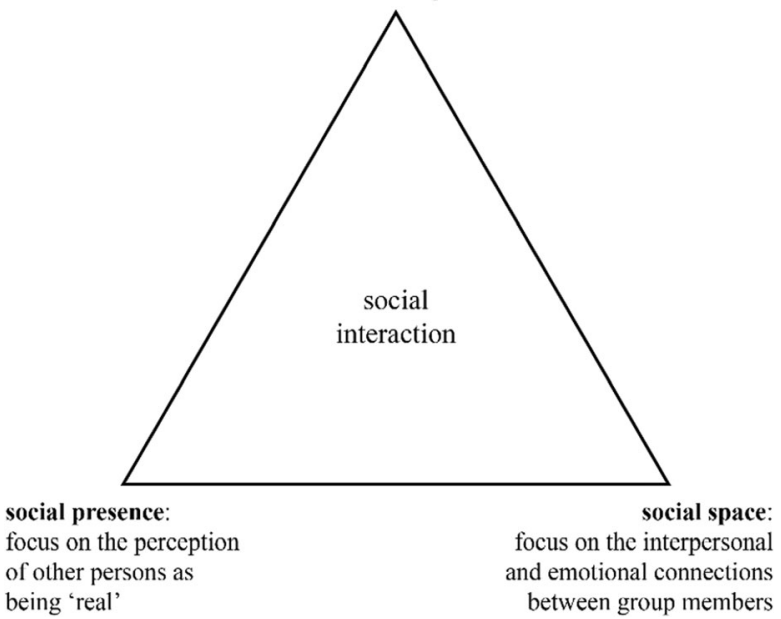

Situation?" section). Rather than "killing" social presence, we describe in the next section how we tried to resolve the confounding situation by disentangling the original social presence theory. We reformulate the definition of social presence and present two interrelated constructs of social presence: social space and sociability (the "Resolving the Confounding Situation" section). We end with a Discussion, a Limitation, and a Conclusion section.

\section{Social Presence and Online Group Learning}

Short et al. (1976) devised social presence theory in order to understand interpersonal communication and relationship building in a business setting when using telecommunication media and how this affects the social influence communication partners may exert on each other. According to them, each telecommunication medium is characterized by the degree to which it can communicate verbal and nonverbal cues conveying socio-emotional information in such a way that the other persons involved in the communication are perceived as physical "real" and present. Accordingly, they defined social presence as the "degree of salience of the other person in the interaction and the consequent salience of the interpersonal relationships" (p. 65). Short et al. (1976) stated that social presence "varies between different media, it affects the nature of the interaction and it interacts with the purpose of the interaction to influence the medium chosen by the individual who wishes to communicate" (p. 65). They further stated that "Social Presence [is] a quality of the medium itself" (p. 65). Thereupon, they could categorize each telecommunication medium according to its degree of social presence by asking respondents to rate the communication media on four seven-point bipolar scales (Short et al., 1976, p. 66): (1) unsociable-sociable (2) insensitive-sensitive (3) cold-warm, and (4) impersonal-personal. Short et al. (1976) related two types of behaviors to social presence, namely, immediacy and intimacy behaviors. According to Short et al. (1976), immediacy is "a 
measure of the psychological distance which a communicator puts between himself and the object of his communication, his addressee or his communication" (p. 72). The concept of immediacy was developed by Wiener and Mehrabian (1968) in face-to-face settings; immediacy behaviors are the verbal and nonverbal approach behaviors that all simultaneously communicate warmth, availability, closeness, and interest. According to Short et al. (1976), intimacy behaviors are "a function of eye-contact, proximity, conversation topic and so on; changes in one will produce compensating changes in the others (...) eye-contact is generally sought after, but too much creates discomfort; for instance, eye-contact is reduced when people are placed very close together" (p. 53). Therefore, Argyle and Dean's (1965) concept of intimacy - also developed in face-to-face settings - is an equilibrium theory postulating that communicators will reach an optimal level of "intimacy" in which conflicting approaches and avoidance forces are in equilibrium. Short et al. (1976) suggested that social presence of the communications media should be included in the list of factors contributing to intimacy.

Gunawardena (1995) was the first to see the potential of using social presence theory and its connection with intimacy and immediacy behaviors in an online distance educational setting to explain student satisfaction with group learning in a text-based computer conference system called GlobalEd. Although she initially defined social presence in line with Short et al.'s (1976) conceptualization of social presence as "the degree to which a person is perceived as a 'real person' in mediated communication" (p. 151), she conceptualized social presence much broader. In her view, social presence is not only a perception but also something that can be created or cultivated by participants. Indeed, Gunawardena (1995) purported that the degree of social presence largely depends on how learners in the GLobalED conference system were able to create social presence: "although CMC is described as a medium that is low in nonverbal cues and social context cues, participants in conferences create social presence by projecting their identities and building online communities" (p. 163). This perspective on social presence as an ability is reiterated in another study: "[r]esearch on social presence and $\mathrm{CMC}$ has indicated that despite the low social bandwidth of the medium, users of computer networks are able to project their identities, whether 'real' or 'pseudo,' feel the presence of others online, and create communities with commonly agreed-upon conventions and norms that bind them together in exploring issues of common interest" (Gunawardena and Zittle, 1997, p. 11). These quotes also show that Gunawardena (1995) linked social presence with community building and social cohesion among participants: GlobalEd despite being "a medium that is low in social context cues, it can be perceived as interactive, active, interesting, and stimulating by conference participants" (p. 147) due to "the kind of interactions that take place between the participants and the sense of community that is created during the conference" (p. 147). As a result, Gunawardena (1995, p. 162) asserted that social presence is largely determined by the user's perception of the medium of CMC as being "social" and not so by the attributes of the communication medium. It is, therefore, that she - in contrast to Short et al. (1976) - asserted that that "immediacy enhances social presence" (p. 151). She measured social presence by extending the four bipolar scales of Short et al. (1976) with 13 other bipolar scales resulting in 17 bipolar scales aimed at soliciting "student reactions on a range of feeling towards the medium of CMC" (p. 150) and, hence, are referred to as the Students" Personal Reactions to CMC scale. However, Gunawardena and Zittle (1997) later maintained that these 17 bipolar scales actually addressed the intimacy aspect of social presence, whereas their newly developed social presence measure is addressing the immediacy aspect of social presence. This latter measure has 14 five-point Likert scale items and is referred to as the Social Presence Scale (SPRES) (see Table 2). To summarize, Gunawardena (1995) saw social 
presence as a perception of the "realness" of the other persons, as an ability to project one's identity in mediated communication, and as community building and social cohesion.

Gunawardena's (1995) perspective on social presence and her findings started a whole new line of research in online distance education wherein the role of social presence is studied in online group learning. In particular, that research is focusing on the relationship of social presence and certain outcomes including the learner satisfaction (Aragon, 2003; Dajani, 2015; Hostetter and Busch, 2006; Moallem, 2015; Richardson and Swan, 2003; So and Brush, 2008), social/group climate (Akyol and Garrison, 2008; Rourke and Anderson, 2002; Tu, 2002a), participation and online interaction (Cui et al., 2013; Danchak et al., 2001; Jorge, 2010; Polhemus et al., 2001; Zhao et al., 2014), perceived learning (Caspi and Blau, 2008; Maddrell, 2011; Richardson and Swan, 2003; Swan and Shih, 2005), learning outcomes (Russo and Benson, 2005; Hostetter, 2013; Madrell, 2011; Shin, 2003; Wei et al., 2012), motivation (Bai, 2003; Robb and Sutton, 2014; Tao, 2009), community building (Lin et al., 2017; Rourke et al., 2001; Rovai, 2002), and dropout (Bowers and Kumar, 2015; Robb and Sutton, 2014).

\section{The Confounding Situation}

\section{Conceptualizations and Definitions of Social Presence}

Unfortunately, what followed this adoption of Short et al.'s (1976) social presence theory in online group learning is an expansion of new interpretations of what social presence is and what it determines. In fact, many conceptualizations and definitions of social presence have come into existence as well as measures for assessing it (Biocca et al., 2001b; Cui, 2013; Kreijns et al., 2014; Lowenthal and Snelson, 2017; Weidlich and Bastiaens, 2017). Table 1 gives an overview of many of these definitions without being exhaustive.

There have been attempts to categorize the different conceptualizations and definitions of social presence. For example, Lowenthal (2010) ordered them on a continuum with on the one end definitions that emphasize perceptions of persons as being "real" and being "there" or "present" (these definitions overlap our definition of social presence, see the "Introduction" section) and on the other end definitions that emphasize the interpersonal connection between participants (these latter definitions overlap our definition of social space; see the Introduction section). According to Lowenthal (2010), most definitions are found in the middle of the continuum but retain some focus for both ends.

Still, some social presence definitions cannot be placed on Lowenthal's social presence continuum because these definitions neither see social presence as a perception nor as an interpersonal connection. For example, Garrison et al. (2000)—building on Gunawardena's (1995) perspective that social presence can be cultivated-reconceptualized it as an ability. Garrison (2009) even went one step further and saw social presence as progressing through the phases (1) acquiring a social identity, (2) have purposeful communication, and (3) building relationships.

Lowenthal's (2010) social presence continuum also falls short regarding the social presence model (SPM) of Whiteside and Garrett Dickers (2016; see also Whiteside, 2015, 2017). They see social presence as a critical literacy for cultivating emotions and relationships, which "serves an influential role in advancing and sustaining successful, meaningful learning experiences" (Whiteside, 2017, p. 133). Their social presence model is used to organize the 
Table 1 Definitions of social presence

Authors Definition

Abdullah (2004)

"a sense that online users have of the communicators being 'real' interlocutors with personalities and physical presence [...]. In other words, an interlocutor's [social presence] is like the impression one would have of him or her if that interlocutor were physically present in the communication" (p. 3)

Arbaugh et al. (2008) "the ability of participants to identify with the community (e.g., course of study), communicate purposefully in a trusting environment, and develop inter-personal relationships by way of projecting their individual personalities" (p.134)

Belderrain (2006) "the degree to which individuals perceive intimacy, immediacy, and their particular role in a relationship" (p. 149)

Biocca et al. (2001a) "the moment-by-moment awareness of the co-presence of another sentient being accompanied by a sense of engagement with the other (i.e., human, animate, or artificial being)"

Garrison (2009)

"the ability of participants to identify with the community (e.g., course or study), communicate purposefully in a trusting environment, and develop interpersonal relationships by way of projecting their individual personalities" (p. 352)

Garrison et al. (2000) "the ability of participants in a community of inquiry to project themselves socially and emotionally, as 'real' people (i.e., their full personality), through the medium of communication being used" (p. 94)

Gunawardena (1995) "the degree to which a person is perceived as a 'real person' in mediated communication" (p. 151).

"[t]he ability to project one's identity" (p. 163).

Gunawardena and Zittle "the degree to which a person is perceived as 'real' in mediated communication" (p. 8) (1997)

Hassanein and Head (2007)

Jung et al. (2002)

Kang et al. (2007)

Kim (2011)

Kozan and Richardson (2014)

Moreno and Mayer (2004)

Picciano (2002)

Ogara et al. (2014)

Remesal and Colomina (2013)

"where the medium gives the user a sense of human warmth and sociability" (p. 690)

"interaction between learners and instructors that occurs when instructors adopt strategies to promote interpersonal encouragement and social integration" (p. 153)

"perceived depth of relationships with other learners and the community during e-learning." (p. 2)

"the specific awareness of relations among the members in a mediated communication environment and the degree of proximity and affiliation formed through it" (p. 766)

"the degree to which participants feel affectively connected to one another" (p. 69)

"[a] feeling of being with and interacting with another social being" (p. 166)

"a student's sense of being in and belonging in a course and the ability to interact with other students and an instructor" (p. 22)

"the degree along some definable continuum of unsociable-sociable, insensitive - sensitive, cold - warm, and impersonal-personal" (p. 455).

"the result of constructive and evolutionary discursive group interaction which promotes the creation of a community feeling, the maintenance of positive relational dynamics, and the enhancement of self- and collective efficacy in front of the learning task, in such a way that the learning process is supported" (p. 258)

Russo (2000)

Short et al. (1976)

the degree to which a person is perceived to be 'real' in a technology mediated environment

"degree of salience of the other person in the interaction and the consequent salience of the interpersonal relationship" (p. 65)

Sung and Mayer (2012) "the subjective feeling of being connected and together with others during computer mediated communication" (p. 1739)

Swan and Shih (2005) "the degree to which participants in computer-mediated communication feel affectively connected one to another" (p. 115)

Whiteside (2017) "a critical literacy for cultivating emotions and relationships, which 'serves an influential role in advancing and sustaining successful, meaningful learning experiences"' (p.133)

Sallnäs (2005) "the feeling that one is present with another person in a mediated environment." (p. 438) 
Table 1 (continued)

\begin{tabular}{ll}
\hline Authors & Definition \\
\hline Shin (2013) & $\begin{array}{c}\text { "a feeling of being in the company of someone and the perceptual illusion of } \\
\text { nonmediation" ( } p \text {. 941) } \\
\text { "Social presence is the degree of person-to-person awareness, which occurs in the } \\
\text { computer environment" (p. 34). }\end{array}$ \\
Tu and McIsaac (2002) & $\begin{array}{l}\text { "[t]he degree of feeling, perception and reaction of being connected to other } \\
\text { intellectual entities in online classrooms" (p.146) } \\
\text { "the degree to which users can feel others" presence in the result of interpersonal } \\
\text { interactions during the communication process" (p. 54). } \\
\text { "the degree of feeling, perception, and reaction of being connected by } \\
\text { computer-mediated communication (CMC) to another intellectual entity through } \\
\text { electronic media" (p.297) }\end{array}$ \\
\hline
\end{tabular}

structure of an online or blended course and encompasses five components: (1) affective association (refers to the emotional connections among participants), (2) community cohesion (refers to the greetings, salutations, and the sharing of various resources), (3) instructor involvement (refers to the encouragement of students to participate in higher order thinking and critical inquiry and on developing relationships and social connections among students), (4) interaction intensity (refers to the level of interaction between students which becomes visible by quoting fellow students or paraphrasing their statements), and (5) knowledge and experience (refers to the prior knowledge and experiences students bring in the course community).

\section{The Measurement of Social Presence}

The many different conceptualizations and definitions of social presence also contributed to the existence of many different measures for it. Table 2 gives an overview of the many social presence measures.

One of the social presence measures that have impacted much the development of other social presence measures is the Social Presence Scale (SPRES) of Gunawardena and Zittle (1997). It has inspired the very influential Community of (CoI) Inquiry model of Garrison et al. (2000), which is centered around three kinds of presences: in addition to social presence, cognitive and teaching presence are essential components of the CoI for developing a complete educational experience. Cognitive presence is the "extent to which learners are able to construct and confirm meaning through sustained reflection and discourse" (Garrison et al., 2001, p. 11), whereas teaching presence is "the design, facilitation, and direction of cognitive and social processes for the purpose of realizing personally meaningful and educationally worthwhile learning outcomes" (Anderson et al., 2001, p. 5). Arbaugh et al. (2008) developed a CoI survey instrument that assesses all three types of presences. Six of the nine items of the CoI survey instrument that form the social presence subscale were derived from SPRES. The CoI survey instrument is currently the most dominant measure in the CoI research community (e.g., Kozan and Richardson, 2014; Saadatmand et al., 2017; Traver et al., 2014). Nevertheless, this instrument has some psychometrical issues to the social presence subscale. While the Arbaugh et al. (2008) validation study revealed three dimensions for the social presence subscale in the CoI survey instrument (group cohesion, open communication, and affective expression; see also Díaz et al., 2010), an empirical study performed by Carlon et al. (2012) showed only two dimensions (social comfort and social experience). Kreijns et al. (2014) 


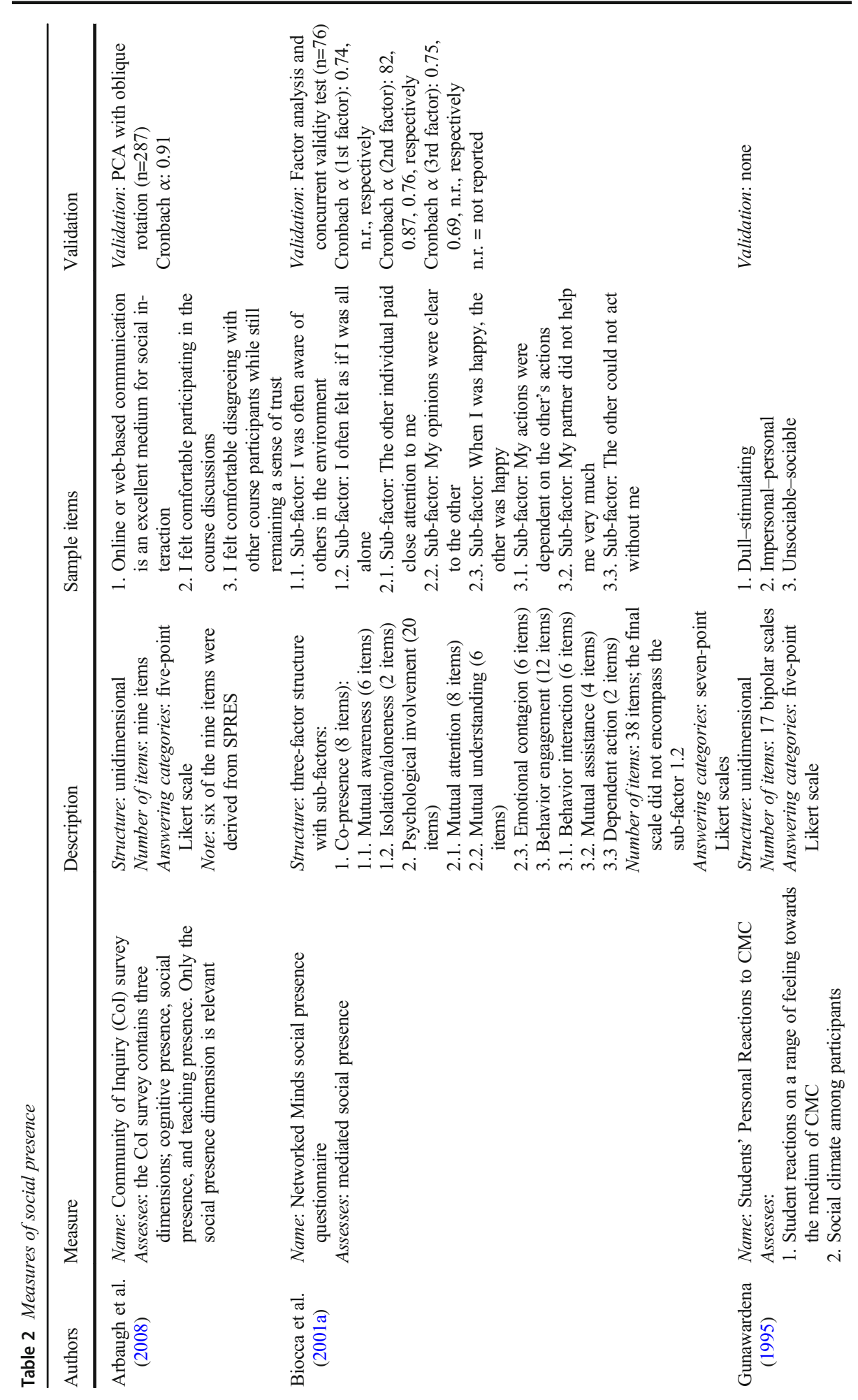




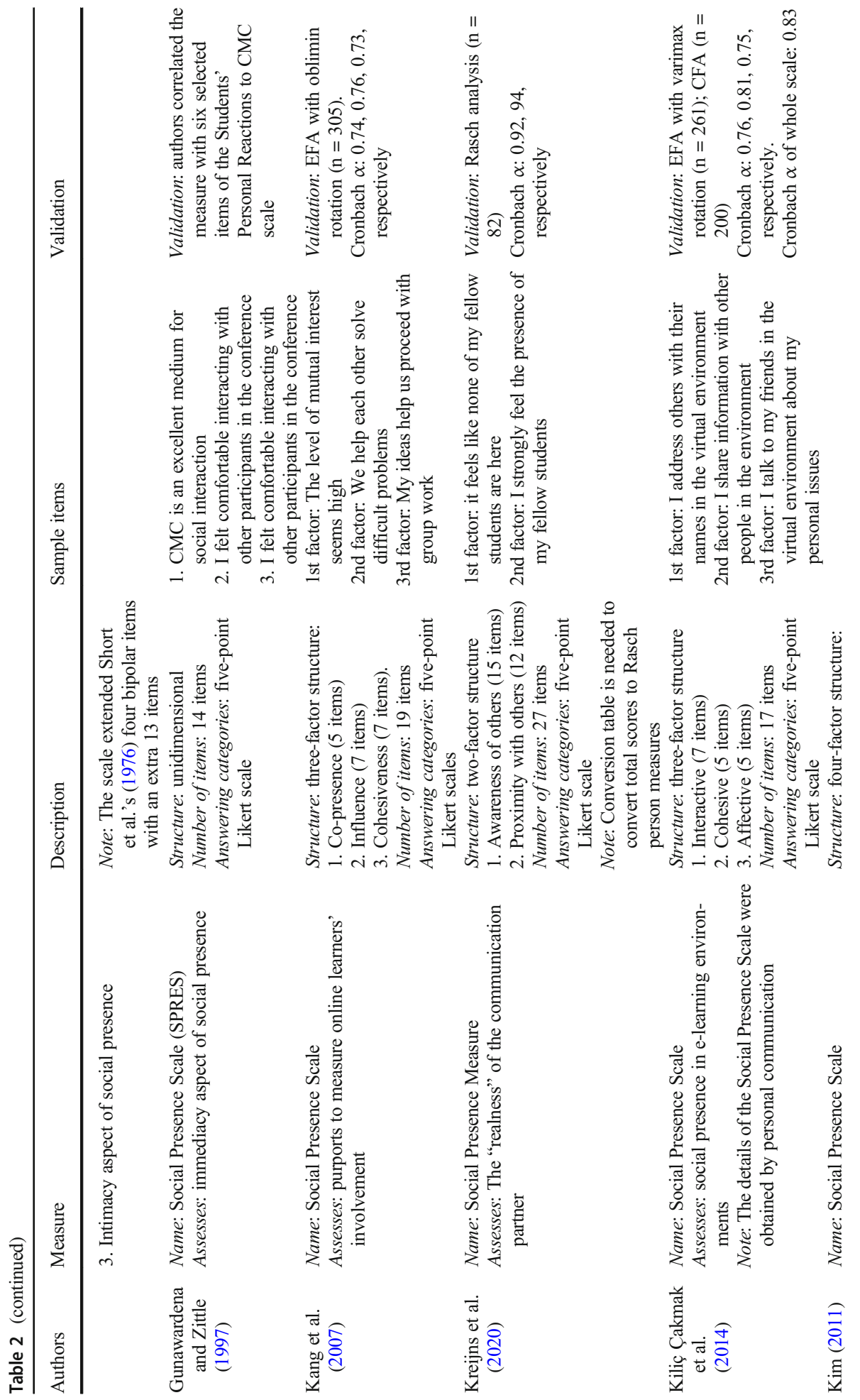




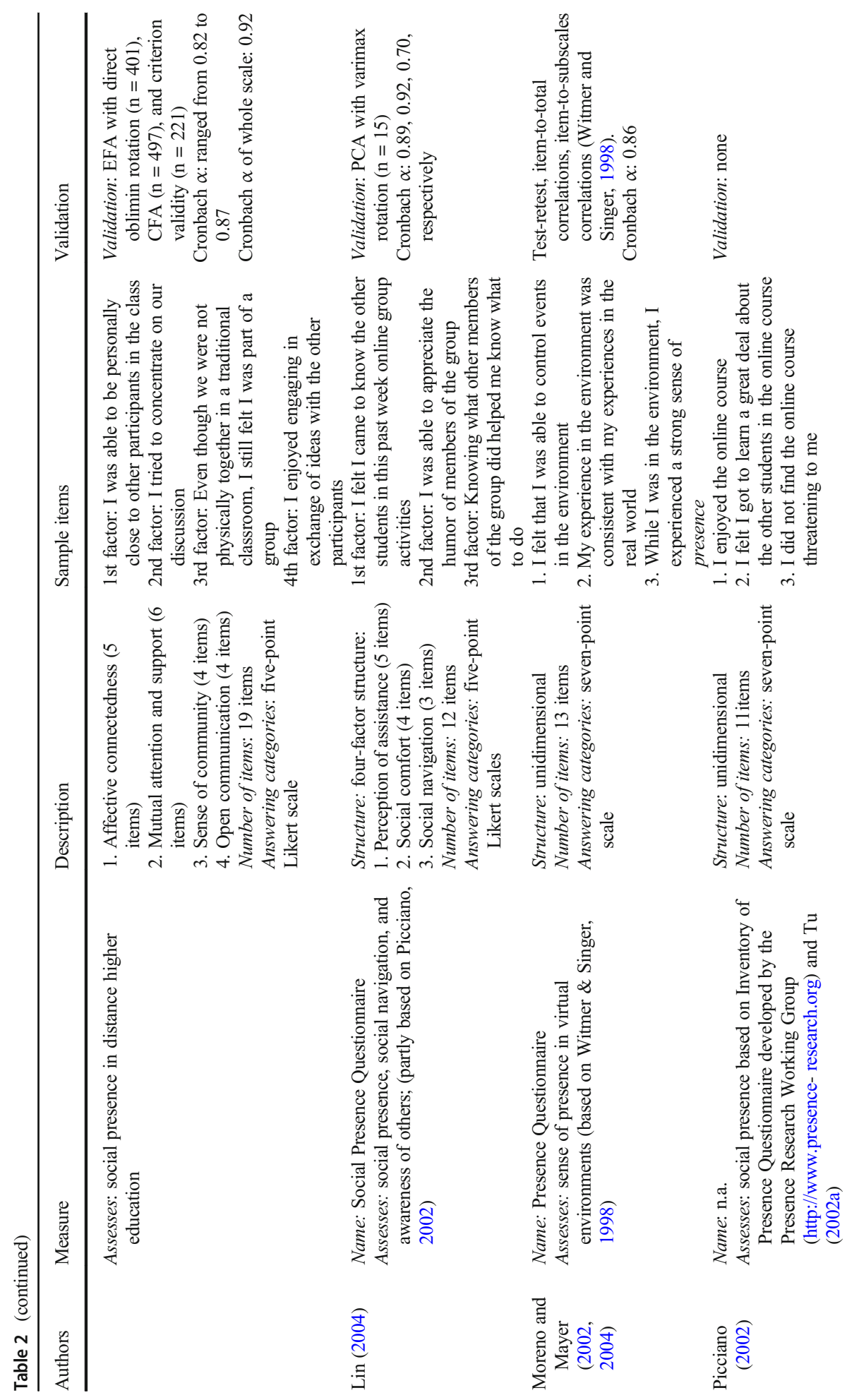




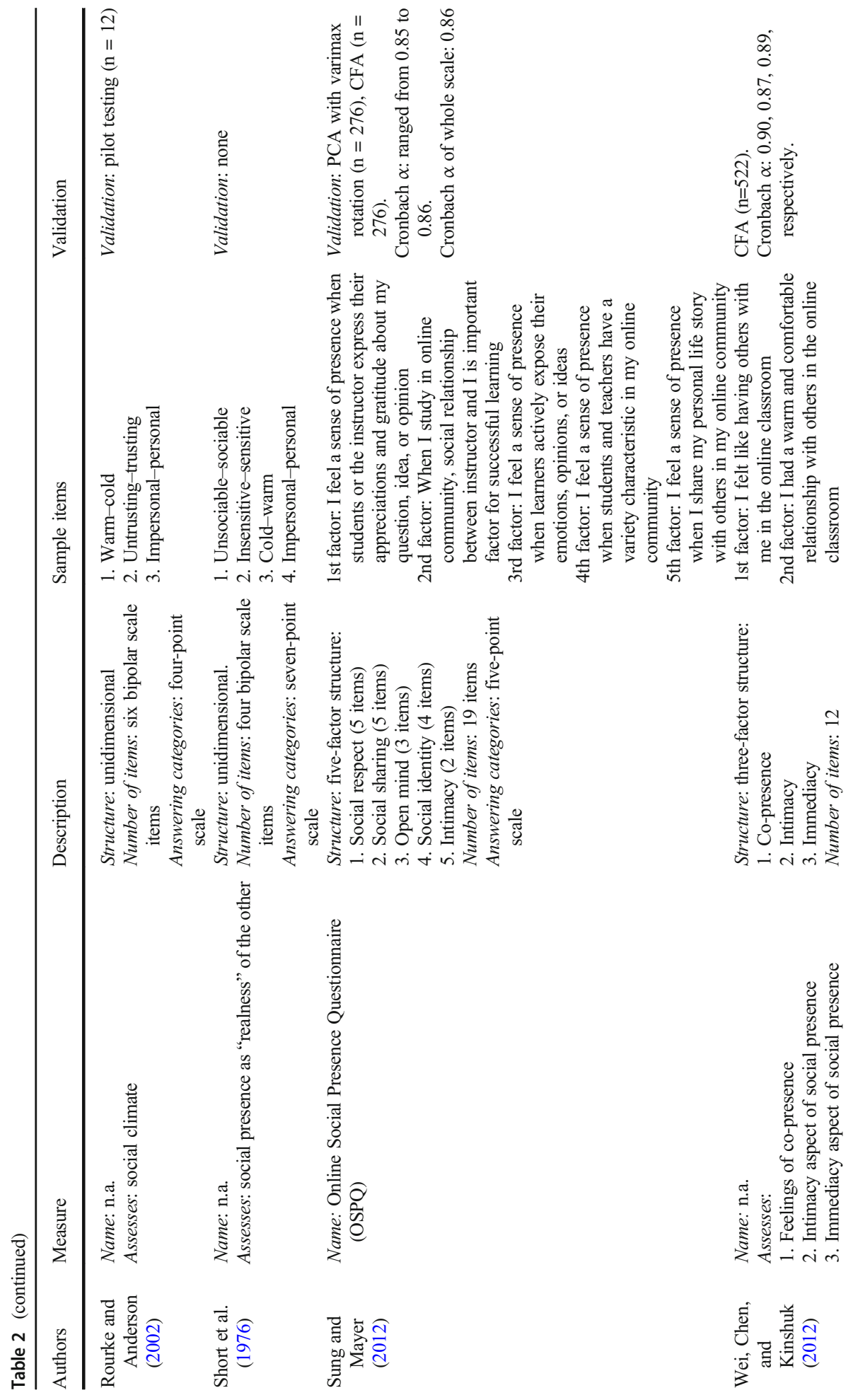




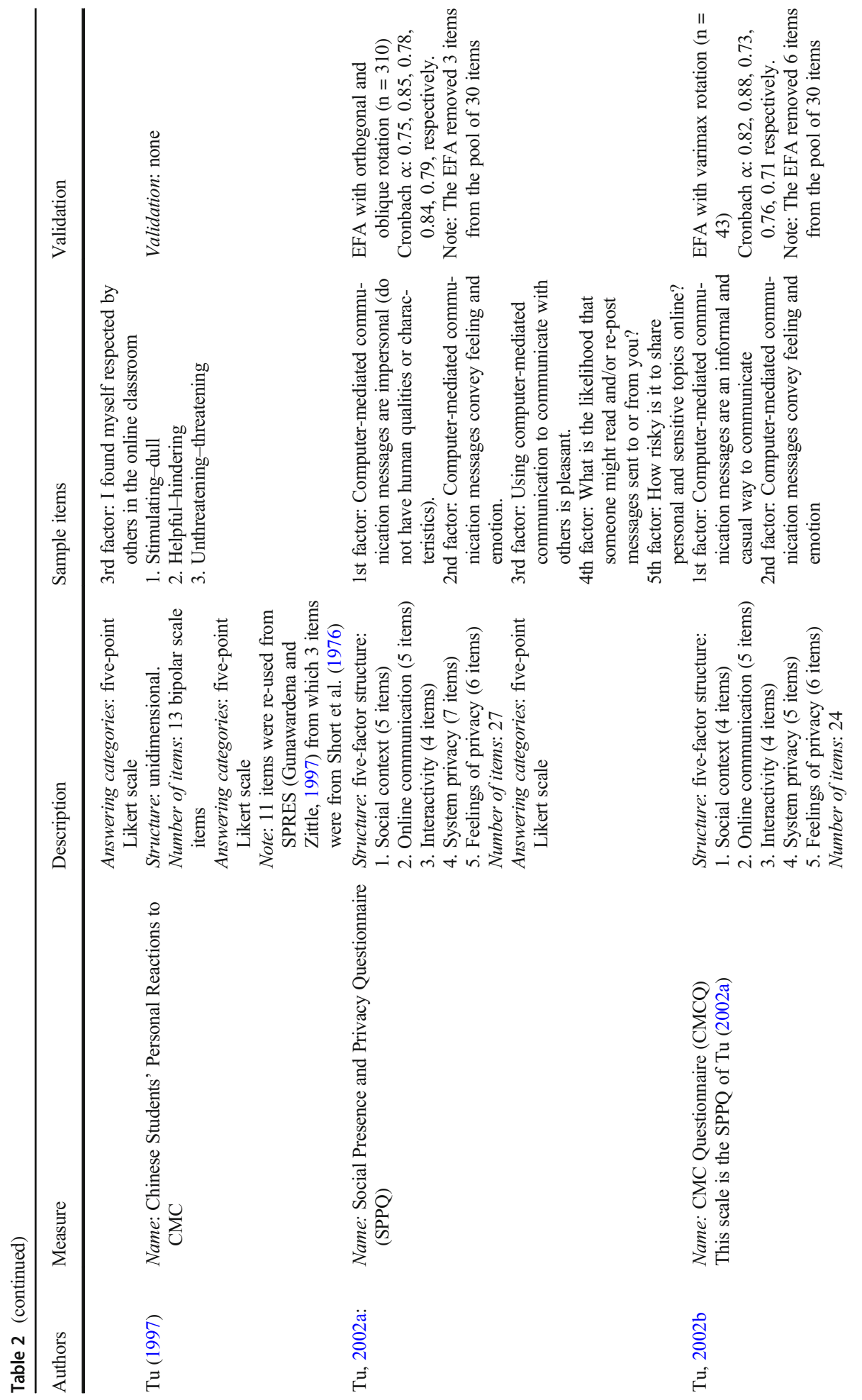




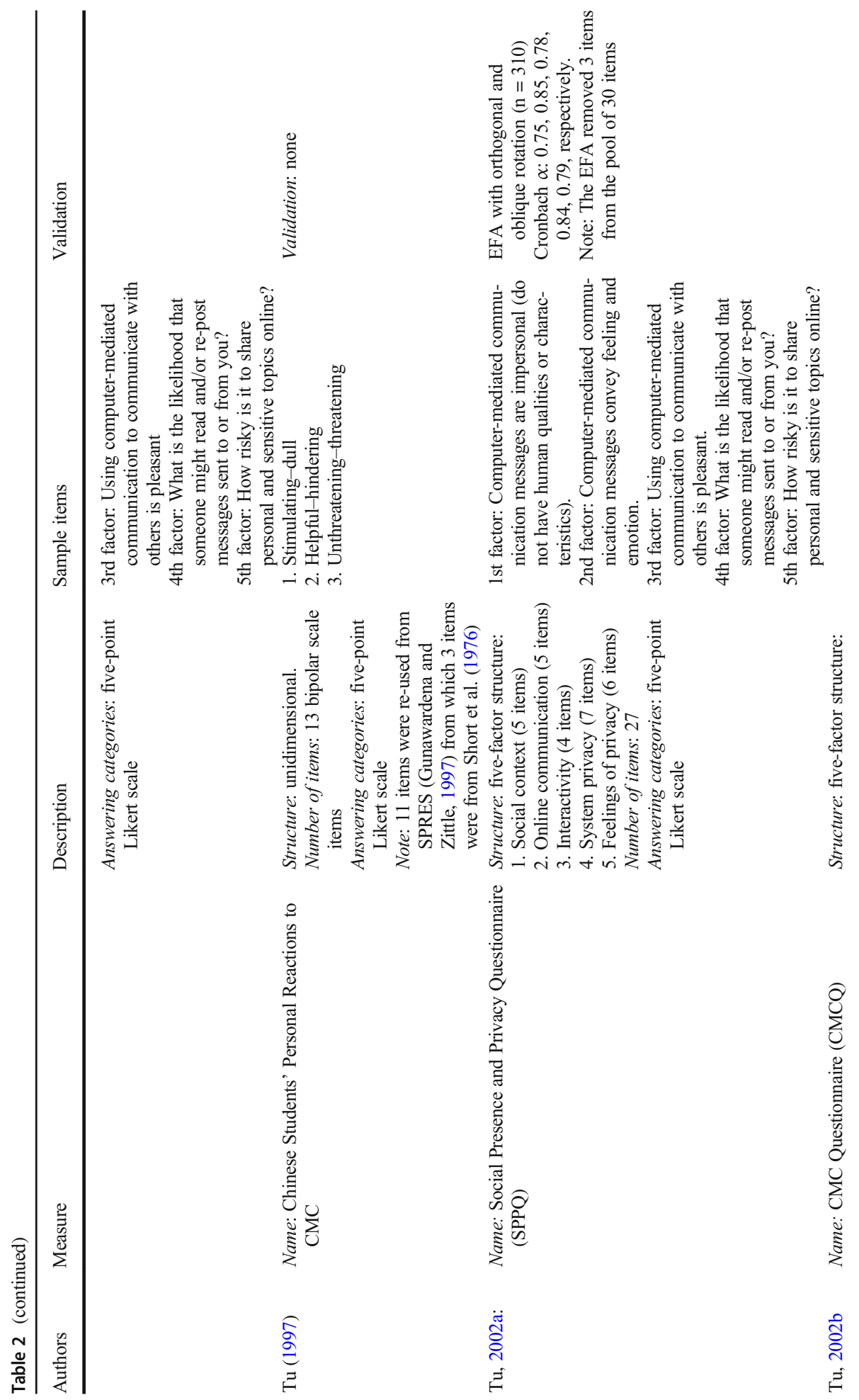




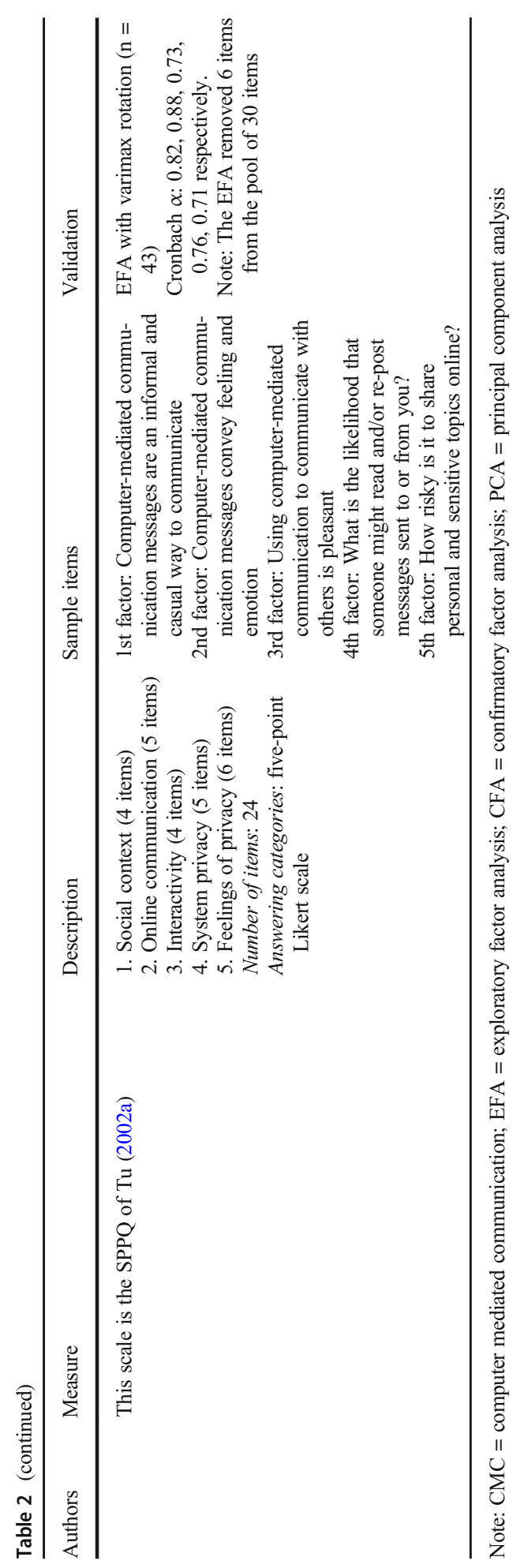


hypothesized that the social presence subscale probably consists out of three dimensions: social space, attitude, and social comfort; they, however, did not provide evidence for it. Recently, Abbitt and Boone (2021) performed Rasch analyses (Rasch, 1960; Bond and Fox, 2015) on the CoI survey instrument and found that the social presence subscale fitted the Rasch measurement model, suggesting a unidimensional scale. However, they did not report whether or not they performed a Rasch test to detect multidimensionality in the subscale to confirm the unidimensionality property.

What is made clear here is that the different measures for social presence make it hard or even impossible to compare the various findings of empirical research using one of these measures because they differ in the number of dimensions as well as what these dimensions are and because the measures do not necessarily assess "realness" of the other person but rather correlates of it (which were then referred to as dimensions). And even if the same dimension is considered (e.g., intimacy), items still may assess a different thing - do the four items of the intimacy dimension of the Wei et al. (2012) measure assess the same thing as the two items of the intimacy dimension of the Sung and Mayer (2012) measure? Again, here too, there is a potential jingle-fallacy.

\section{How Further with the Confounding Situation?}

Kehrwald (2008) stressed that "[a] robust theory of social presence" is needed because it "benefits online teaching and learning by (1) advancing exploration of learning designs which utilize social processes, (2) promoting understanding of the social motivation of users, (3) improving the social affordances of telecommunications systems, and (4) enhancing research into social cognition, interpersonal communication, and theories of mind" (p. 89). But it has already been more than 13 years ago that Kehrwald (2008) remarked that "[d]espite the passage of 30 years since the genesis of social presence theory and more than 10 years since the identification of social presence as a key component of online learning [...], a single, shared understanding of social presence has not emerged" (p. 89). Given the latest developments regarding the social presence construct, we only can see a further increase in entropy of the understanding of what social presence is and how it is measured. Surely, "[t]he lack of a single, shared understanding of social presence is problematic in so far as the improvement of online teaching and learning may be hampered by unexplored assumptions about the nature, role, and function of this critical element of computer-mediated interaction" (Kehrwald, 2008, p. 89). In addition, Chen (2014) pointed out that "social presence [is] still elusive and difficult to define. Due to its ambiguity, many doubts exist related to the measurement of social presence. [...] future researchers should be cautious when advocating the importance of social presence in distance learning" (p. iii). Similarly, Kreijns et al. (2018; see also Biocca et al., 2003; Rettie, 2003) noted that "these issues [...] makes it difficult to compare current findings in the social presence domain and future research is at risk if the confounding situation continues to exist" (p. 32). It is in this context that Lowenthal and Snelson (2017) put forward the question of whether social presence is indeed influencing the degree of perceived learning and learning outcomes as stated by so many social presence researchers. In other words, how do we interpret the findings of the social presence research and their usefulness for designing online learning if different definitions and measures of social presence are used? It is this reason that social presence researchers tend to say to either "kill" social presence (Öztok and Kehrwald, 2017) or call for "future research on social presence and the development of effective 
instrumentation to measure the construct [that] should (a) have a solid conceptualization of social presence, (b) clearly report instrument validity and reliability in published research to allow for the use and selection of effective, valid, and reliable social presence instruments in the field, (c) ensure that media concerns and generalization are taken into consideration, and (d) assess social presence with diverse approaches" (Cui, 2013, p. 26-27). We have chosen to do the latter and outline in the next section our approach.

\section{Resolving the Confounding Situation}

In order to get structure in the conceptual chaos surrounding social presence and its measurement, it seemed to us that the best way is to go back to the original theory of social presence as devised by Short et al. (1976) as to disentangle it. We found that their definition is ambiguous, not operationalizable, and their measurement of it questionable. As a result - and also previewed in the "Introduction" section-we (1) reformulated their social presence definition to enable an operationalization in line with their conceptualization of social presence; (2) departed from their technological determinism of social presence; and (3) identified two other constructs, namely, sociability and social space. In the next subsections, we will go more in-depth on these issues.

\section{Reformulating Short et al.'s Definition of Social Presence}

To recapitulate, Short et al. (1976) defined social presence as the "degree of salience of the other person in the interaction and the consequent salience of the interpersonal relationship" (p. 65). It is easily seen that this definition actually comprises two parts, namely, "degree of salience of the other person in the interaction" and "[degree of] salience of the interpersonal relationship"; the second part is the consequent - but also the purpose - of the first part (Kreijns et al., 2014; Kreijns et al., 2018; see also: Vanden Abeele et al., 2007; Kehrwald, 2008). Because of the two-part definition, it is not clear to distance education researchers adopting social presence theory which part should be emphasized or is more important regarding the characterization of social presence. In addition, it is not clear what is meant by "salience," which opens possibilities for multiple interpretations. Therefore, the definition of Short et al. (1976) is ambiguous and non-operationalizable as the meaning of the underlying latent construct of "salience" remains a point of discussion.

Notwithstanding their ambiguous definition, Short et al. (1976) themselves had a clear view of what social presence is. They emphasized the first part, which they saw as referring to the degree of physical "realness" of the other persons when communicating over communication media that is restricted in transferring verbal and non-verbal cues. This is evidenced by the fact that Short et al. (1976) did explicitly mention on several occasions in their book The social psychology of telecommunications that the degree of social presence is dependent on the degree to which the other person is perceived as a "real" person. For example, on page 73, they stated that for telephone, even when immediacy communication behaviors vary by an interlocutor, the "degree to which he is perceived as a 'real person'- the Social Presence afforded by the telephone - will be the same." On page 74, they pointed to a study of Champness (1973), who evaluated a commercial video system by asking respondents to judge this system by means of a questionnaire containing items like "It provides a great sense of realism" and (negative worded) "People on the other end do not seem 'real'." Lastly, on the same page, they 
clarified that "Social Presence depends upon not only the visual, non-verbal cues transmitted but also more subtle aspects such as the apparent distance of the other (influenced, perhaps, by voice volume) and the 'realness' of the other (influenced, perhaps, by the fidelity of speech reproduction)." The strongest evidence is when Short et al. (1976) expressed their expectation that "[i]t is within the scope of foreseeable technology to reconstitute by electronic means a virtual three-dimensional representation of an individual who is hundreds of miles distant" (in the Preface of their book, p. v). They, apparently, saw such three-dimensional representation as the highest form of fidelity of physical realness of the other. Nowadays, 3D holographic representation of a person has already become a reality (ARHT Media, 2020).

Some social presence researchers do agree with this "realness" aspect of the person and have formulated similar definitions. In addition to the earlier mentioned researchers (see Table 1), we mention Jacobson (2001), who defined social presence as the "[s]ense of being perceived as real when participating in a computer-mediated environment" (p. 653) and Kear (2010), who related social presence "to the need for users to feel connected with each other and to perceive each other as real people" (p. 541). She saw social presence both as perceiving each other as "real" and the need to feel connected.

Regarding the non-operationalization of the definition, if then Short et al. (1976) saw social presence as "realness" of the other persons in the communication, a definition that would incorporate this would make the it operationalizable, as "realness" of the other persons would be the underlying latent construct to be assessed. Therefore, we reformulated the Short et al. (1976) definition as the psychological phenomenon in which, to a certain extent, the others are perceived as physical "real" persons in technology-mediated communication enabled by CMC tools and electronic platforms (see also Kreijns et al., 2014; Kreijns et al., 2018; Weidlich and Bastiaens, 2017, 2019). It, thus, is a sense of other persons being "present" in the "here" and "now" even if this is not true. In other words, social presence is the illusion of being together with other persons as if the communication is not mediated at all by communication media (cf. Lombart and Ditton, 1997).

\section{Short et al. Measurement of Social Presence}

As indicated above, Short et al. (1976, p. 66) used four seven-point bipolar scales to categorize each telecommunication medium according to its degree of social presence. They based their scale on general research on attitudes that is usually assessed by means of a series of bipolar scales (Osgood et al., 1957). The four bipolar scales were: (1) unsociable-sociable, (2) insensitive-sensitive, (3) cold-warm, and (4) impersonal-personal. The more sociable, sensitive, warm, and personal a communication medium is perceived, the higher the social presence experienced. They concluded that face-to-face meetings have the highest degree of social presence, then closed-circuit video channels followed by audio channels, with telephone having the lowest degree of social presence.

However, Short et al. (1976) social presence measure has some psychometrical flaws. First, they did not construct-validate the four bipolar scales and have taken for granted that these scales measure the degree of social presence of the communication medium. Such a position raises the question whether the bipolar scales really are measuring social presence and not something else. Second, the lack of construct validation also means that it is unsure whether the full breadth and depth of social presence are captured by these four bipolar scales (Tu, 2002a; see also Messick, 1996). Third, Short et al. (1976) maintained that social presence is an objective quality of the communication medium. Yet, the four bipolar scales measure the 
subjective quality of this medium because attitudes are assessed toward the communication medium, which would then be "social presence." According to Bradner and Mark (2001), the four bipolar scales form a relative measure of social presence and not an absolute one which most researchers actually need (p. 158).

In conclusion: the four bipolar scales of Short et al. (1976) to measure social presence is questionable for two reasons: (1) there was no construct validation of the measurement instrument, and (2) the measurement instrument did not assess the degree of perceived "realness" of other persons but rather persons' attitude toward a communication medium. Kreijns et al. (2020), therefore, proposed a measure of social presence that operationalizes "realness" of the other persons in the communication in accordance with the reformulated social presence definition. Rasch analyses (Rasch, 1960; Bond and Fox, 2015; Wright and Masters, 1982) were performed to establish construct validity. Thereby, as Short et al. (1976) pointed out that they "conceive of Social Presence as a single dimension representing a cognitive synthesis of all the factors $[\ldots]$ as they are perceived by the individual to be present in the medium" (p. 65), Kreijns et al. (2020) were aiming at a unidimensional social presence measure. However, the Rasch test for multidimensionality revealed two dimensions for social presence, namely, "awareness of others" and "proximity with others"; the former dimension indicates low perceptions and the latter higher perceptions of social presence. The dimensions match some of the social presence definitions in the literature. Definitions supporting one or both dimensions were given by Biocca (1997), who saw awareness of the others as "the minimum level of social presence [which] occurs when users feel that a form, behavior, or sensory experience indicates the presence of another intelligence," Kim (2011) who defined it as "the specific awareness of relations among the members in a mediated communication environment and the degree of proximity and affiliation formed through it" (p. 766), and McLeod et al. (1997) defined social presence as "The degree of tangibility and proximity of other people that one perceives in a communication situation" (p. 708).

\section{Determinants of Social Presence}

Short et al. (1976) devised their social presence theory in the late 1970s. It is, therefore, important to be aware that at that time there was no Internet yet, and all communication happened through communication media that involved the transfer of either video, audio, or a combination of both. In addition, the communication was unbuffered, meaning that it could not be stored and, thus, only immediate (synchronous or real-time) communication was possible. Hence, social presence could only be experienced during these immediate communication episodes while using these media. Therefore, it is - because of this setting - not surprising that Short et al. (1976) were inclined to state that the objective qualities of the communication medium are determining the degree of social presence.

However, as technology became more advanced and the advent of the Internet in the beginning in the early 1980s, other forms of communication media emerged that run on computers. Hence, this type of communication through computers was referred to as computer-mediated communication (CMC). The benefit of CMC is that it can be buffered and stored, meaning that it makes delayed (asynchronous or time-deferred) communication possible. CMC is also mainly text-based, as the usual CMC tools are email, online forums, and instant messaging. Delayed communication allows online distance learning to happen independently of time and place (Chandrasekaran et al., 2016; Harasim, 2012); the same applies to online group learning (Resta and Laferriere, 2007). In this situation, Gunawardena (1995; see 
also Gunawardena and Zittle, 1997) studied social presence experiences in the GlobalEd computer conference system and found other factors were influencing social presence experiences of distance students (see also, Tu, 2002a, 2002b). Indeed, Walther (1993, 1996) already suggested earlier that other factors, that is, factors related to social context, demographics, the individual, the subject of the interaction, and the images that participants have from each other are, are more critical to social presence experiences. Thus, these researchers suggested that not the medium attributes but social factors determine the degree of social presence.

The two lines of research caused what Spears et al. (2000) called the "technological versus social determinism" controversy when they studied social-psychological effects of information and communication technology (ICT) and CMC from different theoretical perspectives that also included social presence theory. They found that, in general, these "theories tend to assume that ICTs' effects are due to characteristics of the technology, or that these are constructed by social factors" (p. 8). Spears et al. (2000), however, concluded from their studies that "the diversity of social effects precludes that technology is singularly good or bad, and that technology determines the social effects. Conversely, social determinism cannot account for invariable technological effects: not every use of ICTs is as flexible as these theories claim. Moreover, social determinism often is relativistic, which restricts its power of prediction and practical use" (p.8). The two lines of research were also indicated by Kehrwald (2008), who named them the "media richness view" and the "relational view," respectively (p. 91).

Today we see that technology has evolved even further and that it goes beyond mere textbased CMC. For instance, chat programs like WhatsApp allow for the exchange of semisynchronous messages that, in addition to text, also may incorporate short footages, emoticons, and animation, which give users endless possibilities to manipulate how other users may perceive their social presence. The same is true for those programs that bear the umbrella term of social software (e.g., Facebook ${ }^{1}$, Instagram ${ }^{2}$, TikTok ${ }^{3}$ ). Also, due to the recent COVID-19 pandemic, we see a growth in the use of real-time video communication applications including Zoom ${ }^{4}$ and Teams meetings ${ }^{5}$. All these latter applications are not CMC tools in the strict sense but are more of an electronic platform wherein you can collaborate with other persons as well. Also, most of these applications may not run only on computers but also on mobile phones and other electronic devices. Not surprisingly, we see increasing use of them in online distance education and OGL.

All these technological developments and their usage in OGL, as well as the new insights on social factors that may influence perceptions of social presence in technology-mediated communication, necessitates that we have to depart from a solely technological determinism of social presence perspective as put forward by Short et al. (1976). We suggest that social presence is codetermined, on the one hand, by the physical attributes of the CMC tools and electronic platforms and, on the other hand, by a contingency of individual and social factors such as personality, motivations, social context, social processes, and so forth. In other words, we adhere to the perspective that social presence is only partly determined by technology attributes.

Social determinism may be emphasized when dealing with present-day electronic OGLplatforms like BrightSpace and Canvas where the communication is predominantly delayed and text-based. As a matter of fact, the dominant and preferred way of delayed communication

\footnotetext{
${ }^{1} \mathrm{http}: / /$ www.facebook.com

$2 \mathrm{http}: / /$ www.instagram.com

${ }^{3} \mathrm{http}: / /$ www.tiktok.com

${ }^{4}$ http://www.zoom.us

${ }^{5}$ https://www.microsoft.com/en-us/microsoft-teams/group-chat-software
} 
is still text-based (Ansari and Phillips, 2011). Technological determinism may be emphasized when dealing with electronic group learning environments based on VR applications (e.g., Oksanen and Hämäläinen, 2013; see also Oh et al., 2018). In these environments, the human body is represented by avatars that may or may not be ultra-realistic. Ultra-realistic avatars are currently implemented in Facebook Reality Labs (FLR, 2021) to see what it means for social presence experiences. FRL stated that their "goal is to make virtual interactions feel as natural as in-person interactions. We call this 'social presence.' It's the 3D-enabled feeling that you're physically sharing the same space with someone else, even though you may be miles apart and that you can communicate your ideas and emotions seamlessly and effortlessly. To accomplish that in VR, you need lifelike avatars - virtual stand-ins that faithfully reproduce your facial expressions, gestures, and your voice." We believe that such ultra-realistic avatars would be entirely in line with what Short et al. (1976) projected of what social presence is.

\section{Two Related Constructs of Social Presence: Social Space and Sociability}

From the above (and hinted in the "Introduction" section), we already made clear that social presence is interrelated with two other constructs implied by Short et al.'s (1976) social presence theory, namely, social space and sociability. In the following sections, we describe more in-depth what these constructs are.

Social Space As pointed out, Short et al.'s (1976) definition can be seen as consisting out of two parts, namely: "degree of salience of the other person in the interaction" (the first part) and "[degree of] salience of the interpersonal relationship" (the second part). Thereby, the second part is the consequence of the first part. Short et al. (1976) saw the development of interpersonal relationships separated from the salience of the other person when they discussed the significance of knowing someone already when telecommunication media are used (Chapter 8). Thus, rather than being part of the same social presence construct as implied by the original definition, we consider this second part as a related but different construct than social presence. This related construct is designated to be social space (Kreijns et al., 2004), which we define as the network of interpersonal relationships embedded in group structures of norms and values, rules and roles, and beliefs and ideals. A sound social space is manifested by a sense of community, group climate, mutual trust, social identity, and group cohesion. As such, social space can be seen as a group attribute. This definition will now be elaborated.

In accordance with the social network perspective (Katz et al., 2004), we see each interpersonal relationship as a tie that connects two communicating persons whereby these ties may be weak or strong. Consequently, all interpersonal relationships span a kind of space; hence, we speak of a social space. As mentioned above, all the interpersonal/social relationships are embedded within the group's norms and values, rules and roles, and beliefs and ideals (see also: Blanchard and Markus, 2004; Brook and Oliver, 2002). Thus, apart from the spatial structure, social space also has a cultural structure because norms and values, rules and roles, and beliefs and ideals are cultural artifacts developed and maintained by the group members. Forsyth (2013), taking up a different perspective, identified four structures, a normative structure, an affective structure, a communication structure, and a role structure, but essentially, these structures come down to the same cultural artifacts mentioned above. Within these structures, communicating persons may experience a shared social identity, group cohesiveness, connectedness with others, mutual trust, a sense of belonging, a sense of community, a social climate, and an open atmosphere. Hence, we speak of a social space. 
If these qualities exist in a positive way, we may designate the social space to be sound, such that it becomes a space for learning, thereby enabling productive social interaction for collaborative learning. Indeed, Johnson and Johnson (2009, see also Haythornthwaite, 2002, Moore \& Kearsley, 1996, Palloff and Pratt, 1999, 2005) pointed out that good interpersonal relationships and a sense of community need to exist in order for social interaction for collaborative learning to take place, and vice versa, the collaboration will reinforce the sense of community. With regard to mutual trust, Johnson and Johnson (1989) pointed to its importance: "[t]o disclose one's reasoning and information, one must trust the other individuals involved in the situation to listen with respect" (p. 72). Moreover, mutual trust is needed because group members will not participate collaboratively if they do not know with whom they are communicating (Smith and Kollock, 1998). Therefore, "trust is a central element in the provision of both a safe environment for learners and the conditions for communication and collaboration" (Jones et al., 2006, p. 50). Hara et al. (2000) concluded that in OGL, strategies promoting the sense of connectedness and belonging are critical for the learner. In fact, "[s]ocial presence helps to realise collaboration through establishing a warm and collegial learning community to encourage participation and interaction" (Zhao et al., 2014, p. 807). In addition, "[a] good atmosphere of learning interaction will be created when learners can perceive a high degree of social presence" (Wei et al., 2012, p. 533).

However, all the qualities mentioned here are not independent of each other but for the greater part overlap each other. In particular, sense of community seems to have the biggest overlap with most of the mentioned qualities. Sense of community originates from the work of Sarason (1974), who defined sense of community as "the sense that one [is] part of a readily available, mutually supportive network of relationships upon which one could depend and as a result of which one [does] not experience sustained feelings of loneliness" (p. 1). Trust seems to be an element of group climate (Brahm and Kunze, 2012). Given all these qualities that reinforce the social interaction in OGL groups, it is not surprising that many social presence researchers see these qualities as "social presence" - see, for example, Gunawardena (1995) and Rourke and Anderson (2002).

Sociability We already addressed the fact that Short et al. (1976) apparently saw social presence to be determined solely by the physical attributes of the communication media, thus, their capacity to transfer verbal and nonverbal cues that allow for, to a certain degree, social presence experiences. Their four bipolar scales were meant to measure this capacity. However, as we pointed out above, there was no construct validation performed on the scales. It, therefore, is the question whether the bipolar scales really measure social presence as "realness" of the other persons. We believe that these bipolar scales are referring to yet another construct which is designated to be sociability (Kreijns et al., 2002). We define sociability as the capacity of CMC tools and electronic platforms to allow for the expression of social presence, the experience of it, as well as for the emergence of a social space. As such, sociability is a medium attribute. The definition aligns with Walther's (1993) social information processing theory that distinguishes between impression management and impression formation in $\mathrm{CMC}$; the impression is the mental model one has over the other person. Through impression management, persons may give expression to their social presence, and by impression formation, persons may experience the social presence of other persons.

We have labeled this capacity sociability after one of the bipolar scales of Short et al. (1976), namely, the "unsociable-sociable"-bipolar scale. In the case of OGL, the CMC tools and electronic platform may be the electronic learning platform used by the OGL groups. 
These platforms include proprietary platforms such as Canvas $^{6}$ and Brightspace ${ }^{7}$ or opensource platforms such as Moodle ${ }^{8}$ and Elgg 9 .

Sociability as a capacity of CMC tools and electronic platforms is considered an attribute of these and, therefore, can be designed. Kreijns et al. (2002) have designated the particular functionalities that make up the sociability of CMC tools and electronic platforms to be social affordances (see also Kirschner and Kreijns, 2005). A canonical example of a physical social affordance device is the coffee machine where people meet by chance and have some small talk, usually about daily things that happened outside office hours. Although small talk may not necessarily contribute to formal communication or to learning, they do have a function with respect to the development of trustworthy interpersonal relationships and therewith to the social space, which may be beneficial when a work-related conversation is needed or when group work has to be done. It is this kind of social affordances that we seek to be present in electronic OGL platforms (see also Weidlich and Bastiaens, 2019).

It is purported that social media (Facebook, Instagram, TikTok) is high on sociability because they possess many types of social affordances; hence, they are deemed "social media." The kind of social affordances found in these social media encompass, among others, possibilities for self-expression, personalizing, the upload of videos and photos for sharing, commenting on messages of other persons, blogging, grouping, and the use of a variety of emoticons when instant messaging. However, while indeed the availability of these affordances explains why social media has become so popular (Gao et al., 2010), it is also the hedonic affordances that contributed much to their popularity $(\mathrm{Li}, 2011)$.

Hedonic affordances determine the hedonicity of an electronic platform which is yet another medium attribute; and in the case of an electronic OGL platform, a third medium attribute is educability (Kreijns and Kirschner, 2018). Hedonicity expresses the extent to which $\mathrm{CMC}$ tools and electronic platforms support pleasure and enjoyment experiences during the course of working on group tasks. Past research on the adoption of technological devices and software systems has shown that hedonicity is an important factor in the adoption of these devices and systems and their continuous usage (Davis et al., 1992; Nysveen et al., 2005). Educability is the capacity of the electronic OGL platform to facilitate group learning by providing the educational affordances to support it. Educational affordances encompass shared work spaces (e.g., a shared whiteboard, a shared text processor), collaboration tools (e.g., a mind map tool, an argumentation space), and tools for feedback and reflection. It is expected that electronic OGL platforms do possess a certain minimum of educational affordances; otherwise, these platforms will be rendered useless for group learning.

\section{Discussion}

Social presence is an evocative and popular notion. There have now been decades of research into the concept and its many applications in different domains. Yet, this has not produced a clear understanding of the concept and caused a situation that brings much confusion

\footnotetext{
$\overline{{ }^{6} \mathrm{https}: / / \mathrm{www} . \text { instructure.com/en-gb }}$

${ }^{7}$ http://www.d21.com

${ }^{8}$ http://www.moodle.com

${ }^{9} \mathrm{http}: / /$ www.elgg.org
} 
preventing the development of a coherent research field regarding social presence and its defining role in OGL. Subsequently, there have been numerous calls for more rigor in social presence research (Biocca et al., 2003; Öztok and Kehrwald, 2017; Lowenthal and Snelson, 2017).

The purpose of this paper was to disentangle social presence theory as devised by Short et al. (1976). We found, in essence, a strikingly severe case of the jingle-fallacy. This undesirable state of research, first formulated by Thorndike (1904), has been found to be present in many areas of psychology (e.g., Higgs and Lichtenstein, 2010; Larsen and Bong, 2016; Weidman et al., 2017) and appears to apply to social presence research as well. Indeed, by the disentanglement of social presence theory, we identified two other constructs, social space and sociability, that are closely linked with social presence yet separated from it. Nevertheless, social presence researchers often treat them as one, as if they all were "social presence."

Potential consequences of this are, at best, an inconvenience for emerging scholars who are not steeped in the literature, at worst, effectively obstructing cumulative research of a concept that may be pivotal for understanding interpersonal effects in OGL contexts that are increasingly technologically mediated.

Although our work is not the first of its kind, the goal of this paper was to provide something the previous work has not, a possibility to integrate and incorporate the myriad of ways social presence has been defined in the past. For example, Lowenthal's (2010) continuum was an elegant statement of a foundational problem in the literature on social presence. Due to its bipolar structure, however, it did not account for the one conception of social presence that has been so foundational in its history; the idea of intrinsic qualities of the medium or the environment to foster these interpersonal experiences. That is, it did not account for the prevalent conflation of social presence with sociability and social space.

Instead of merely showing what is out there and pointing to the deficiencies of the literature, we aimed to provide a way out, a framework through which we can better understand past research. Through this, we avoid the tendency of defiling or invalidating this large body of research and instead provide one step toward resolution. We found that definitions and measurement of social presence can be allocated in a space between three interrelated constructs, sociability, social presence, and social space. With this framework at hand, we can better understand the many correlates and effects that have been attributed to social presence but that may, in fact, be better attributed to sociability or social space.

As an example, let us consider the elusive connection of social presence to learning achievement. This connection is claimed by many (Wei et al., 2012; Molinillo et al., 2018), but convincing evidence is quite rare (Chen, 2014). Upon further reflection, one also notices the lack of a plausible mechanism for this connection. Why should the "realness" of the communication partner - or the illusion of non-mediation - exert causal influence on cognitive learning achievement? On the other hand, we have the notion of social space, which encapsulates group cohesion, mutual trust, and learning climate, aspects that have been consistently shown to be conducive to learning (Gunawardena, 1995; Rourke and Anderson, 2002; Rovai, 2002; Williams et al., 2006). A measurement of social presence that is entangled with social space will then naturally produce an association with learning achievement, which, however, should not be attributed to social presence. Confusions like these need to be avoided to make cumulative progress possible, both in our theoretical understanding of social presence and the practical application of this knowledge. 


\section{Limitations}

Although we aimed to provide a comprehensive review of the issues surrounding the definition and measurement of social presence, it remains possible that we have missed exemplary single studies or even lines of research that operate with coherent definitions and rigorous measures. However, we are confident that we have captured a large part of the most well-known and well-cited social presence research and, given the prevalence of issues in our reviewed sample, we find it unlikely that research we may have missed has fared significantly better in terms of defining and measuring social presence.

Importantly, our paper focused on the educational domain, more specifically, the realm of online distance learning, where OGL plays a large role. There are, of course, other areas of research that work with the concept of social presence, for example, VR, robotics, and conversational agents (see, e.g., Oh et al., 2018; Luria et al., 2019) and online shopping (Hassanein and Head, 2007; Ogonowski et al., 2014). In this sense, our literature review is limited. Yet, we have reasons to believe that these contexts are sufficiently different from most practices in online distance learning to warrant the exclusion of these research lines. Notably, they also grapple with the definition and measurement of their focal constructs (Slater, 2004; Hein et al., 2018).

Finally, our proposed solution of differentiating three central constructs appears sensible in light of the original definition of Short et al. (1976) and the research that has emerged since then. Still, it is of course possible that our rather narrow definition focusing on the "realness" of the communication partner will not be accepted by other scholars, who may prefer a richer conception of social presence, for example, one that encompasses affective and group climaterelated aspects.

\section{Conclusion}

Aiming for conceptual clarity, researchers concerned with social presence are encouraged to distinguish between the three major variables delineated in this paper. Thus, we recommend referring to sociability when we wish to talk about the capacity of CMC tools and electronic platforms when it comes to giving expression to one's social presence and how one is perceiving or experiencing the other person's social presence so to foster socio-emotional aspects of the learning experience. If, on the other hand, we consider the extent to which there is a network of interpersonal relationships in the OGL-group, we should refer to the term social space, which considers sense of community, group climate, mutual trust, social identity and group cohesion. Lastly, let's only talk about social presence when we want to invoke the unique psychological phenomenon that we perceive other social persons as being physical "real" persons while using CMC tools and electronic platforms. Only then can we escape from the confounding situation surrounding social presence and build a coherent and cumulative research line.

\section{Declarations}

Conflict of Interest The authors declare that they have no conflict of interest. 
Open Access This article is licensed under a Creative Commons Attribution 4.0 International License, which permits use, sharing, adaptation, distribution and reproduction in any medium or format, as long as you give appropriate credit to the original author(s) and the source, provide a link to the Creative Commons licence, and indicate if changes were made. The images or other third party material in this article are included in the article's Creative Commons licence, unless indicated otherwise in a credit line to the material. If material is not included in the article's Creative Commons licence and your intended use is not permitted by statutory regulation or exceeds the permitted use, you will need to obtain permission directly from the copyright holder. To view a copy of this licence, visit http://creativecommons.org/licenses/by/4.0/.

\section{References}

Abbitt, J. T., \& Boone, W. J. (2021). Gaining insight from survey data: an analysis of the community of inquiry survey using Rasch measurement techniques. Journal of Computing in Higher Education. https://doi.org/10. 1007/s12528-020-09268-6.

Abdullah, M. H. (2004). Social presence in online conferences: what makes people 'real'? Malaysian Journal of Distance Education, 6(2), 1-22.

Akyol, Z., \& Garrison, D. R. (2008). The development of a community of inquiry over time in an online course: understanding the progression and integration of social, cognitive and teaching presence. Journal of Asynchronous Learning Networks, 12(3-4), 3-22.

Anderson, T., Rourke, L., Garrison, D. R., \& Archer, W. (2001). Assessing teaching presence in a computer conferencing context. Journal of Asynchronous Learning Networks, 5(2), 1-17.

Ansari, S., \& Phillips, N. (2011). Text me! New consumer practices and change in organizational fields. Organization Science, 22(6), 1579-1599. https://doi.org/10.1287/orsc.1100.0595.

Aragon, S. R. (2003). Creating social presence in online environments. New Directions for Adult and Continuing Education, 2003(100), 57-68.

Arbaugh, J. B., Cleveland-Ines, M., Diaz, S., Garrison, D. R., Ice, P., Richardson, J., Shea, P., \& Swan, K. (2008). Developing a community of inquiry instrument: testing a measure of the community of inquiry framework using a multi-institutional sample. The Internet and Higher Education, 11(3-4), 133-136.

Argyle, D., \& Dean, J. (1965). Eye contact, distance and affiliation. Sociometry, 28(3), 289-304.

ARHT Media (2020). Holographic telepresence. Available from: https:/www.arhtmedia.com/.

Bai, H. (2003). Student motivation and social presence in online learning: implications for future research. In C. Crawford, N. Davis, J. Price, R. Weber, \& D. Willis (Eds.), Proceedings of SITE 2003-Society for Information Technology \& Teacher Education International Conference (pp. 2714-2720). Association for the Advancement of Computing in Education (AACE).

Belderrain, Y. (2006). Distance education trends: integrating new techniques to foster student interactions and collaboration. Distance Education, 27(2), 139-154.

Biocca, F. (1997). The cyborg's dilemma: progressive embodiment in virtual environments. Journal of Computer-Mediated Communication, 3(2). https://doi.org/10.1111/j.1083-6101.1997.tb00070.x.

Biocca, F., Harms, C., \& Gregg, J. (2001a). The networked minds measure of social presence: pilot test of the factor structure and concurrent validity. In Proceedings of the Fourth Annual international presence workshop (Presence 2001). Philadelphia, PA. Available from: https://ispr.info/presence-conferences/ previous-conferences/presence-2001/

Biocca, F., Burgoon, J., Harms, C., \& Stoner (2001b), Criteria and scope conditions for a theory and measure of social presence. In Proceedings of the Fourth Annual international presence workshop (Presence 2001). Philadelphia, PA. Available from: https://ispr.info/presence-conferences/previous-conferences/presence2001/

Biocca, F., Harms, C., \& Burgoon, J. (2003). Toward a more robust theory and measure of social presence: review and suggested criteria. Presence Teleoperators and Virtual Environments, 12(5), 456-480. https:// doi.org/10.1162/105474603322761270.

Blanchard, A. L., \& Markus, M. L. (2004). The experienced 'sense' of virtual community: characteristics and processes. The Database for Advances in Information Systems, 35(1), 65-79.

Bond, T., \& Fox, C. M. (2015). Applying the Rasch model: fundamental measurement in the human sciences (3rd ed.). Routledge.

Bowers, J., \& Kumar, P. (2015). Students' perceptions of teaching and social presence: a comparative analysis of face-to-face and online learning environments. International Journal of Web-Based Learning and Teaching Technologies, 10(1), 27-44. 
Bradner, E., \& Mark, G. (2001). Social presence with video and application sharing. In T. Rodden, C. Ellis, \& I. Zigurs (Eds.), GROUP '01: Proceedings of the 2001 International ACM SIGGROUP Conference on Supporting Group Work (pp. 154-161). ACM.

Brahm, T., \& Kunze, F. (2012). The role of trust climate in virtual teams. Journal of Managerial Psychology, 27(6), 595-614. https://doi.org/10.1108/02683941211252446.

Brook, C., \& Oliver, R. (2002). Supporting the development of learning communities in online settings. In P. Barker \& S. Rebelsky (Eds.), Proceedings of the ED-MEDIA 2002 - World conference on educational multimedia, hypermedia \& telecommunications (pp. 192-197). AACE.

Carlon, S., Bennett-Woods, D., Berg, B., Claywell, L., LeDuc, K., Marcisz, N., Mulhall, M., Noteboom, T., Snedden, T., Whalen, K., \& Zenoni, L. (2012). The community of inquiry instrument: validation and results in online health care disciplines. Computers in Education, 59(2), 215-221.

Caspi, A., \& Blau, I. (2008). Social presence in online discussion groups: testing three conceptions and their relations to perceived learning. Social Psychology of Education, 11(3), 323-346.

Champness, B. G. (1973). Attitudes toward person-person communications media. Human Factors: The Journal of the Human Factors and Ergonomics Society, 15(5), 437-447. https://doi.org/10.1177/ 001872087301500501.

Chandrasekaran, S., Badwal, P. S., Littlefair, G., \& Muhlfelder, M. (2016). Framework guidelines for students: collaborative learning in distance education. Journal of Modern Education Review, 6(12), 940-951.

Chen, X. (2014). An integrative review of the effects of social presence on distance education (Doctoral dissertation). Virginia Polytechnic Institute and State University. Available from: https://pdfs. semanticscholar.org/ff58/571164739cc48c24e048555a0928450a2bb7.pdf.

Cui, G. (2013). Evaluating online social presence: an overview of social presence assessment. Journal of Educational Technology Development and Exchange, 6(1), 13-30.

Cui, G., Lockee, B., \& Meng, C. (2013). Building modern online social presence: a review of social presence theory and its instructional design implications for future trends. Education and Information Technologies, $18(4), 661-685$.

Dajani, F. K. (2015). Examining social presence influence on students' satisfaction with online learning environments. In A. G. Scheg (Ed.), Critical examination of distance education transformation across disciplines. IGI Global. https://doi.org/10.4018/978-1-4666-6555-2.ch011.

Danchak, M. M, Walther, J. B., \& Swan, K. P. (2001). Presence in mediated instruction: bandwidth, behaviour, and expectancy violations. Paper presented at the 7th Sloan-C International Conference on Asynchronous Learning Networks, Orlando, FL.

Davis, F. D., Bagozzi, R. P., \& Warshaw, P. R. (1992). Extrinsic and intrinsic motivation to use computers in the workplace. Journal of Applied Social Psychology, 22(14), 1111-1132.

Díaz, S. D., Swan, K., Ice, P., \& Kupczynski, L. (2010). Student ratings of the importance of survey items, multiplicative factor analysis, and the validity of the community of inquiry survey. The Internet and Higher Education, 13(1-2), 22-30.

FLR (2021). Inside Facebook Reality Labs: research updates and the future of social connection. Available from: https://tech.fb.com/inside-facebook-reality-labs-research-updates-and-the-future-of-social-connection/.

Forsyth, D. R. (2013). Group Dynamics (6th ed.). Cengage Learning.

Gao, Q., Dai, Y., Fan, Z., \& Kang, R. (2010). Understanding factors affecting perceived sociability of social software. Computers in Human Behavior, 26(6), 1846-1861. https://doi.org/10.1016/j.chb.2010.07.022.

Garrison, D. R. (2009). Communities of inquiry in online learning. In P. L. Rogers (Ed.), Encyclopedia of distance learning (2nd ed., pp. 352-355). IGI Global.

Garrison, D. R., Anderson, T., \& Archer, W. (2000). Critical inquiry in a text-based environment: computer conferencing in higher education model. The Internet and Higher Education, 2(2-3), 87-105.

Garrison, D. R., Anderson, T., \& Archer, W. (2001). Critical thinking, cognitive presence, and computer conferencing in distance education. American Journal of Distance Education, 15(1), 7-23.

Giesbers, B., Rienties, B., Tempelaar, D. T., \& Gijselaers, W. (2014). Why increased social presence through web videoconferencing does not automatically lead to improved learning. E-Learning and Digital Media, 11(1), 31-45. https://doi.org/10.2304/elea.2014.11.1.31.

Gunawardena, C. N. (1995). Social presence theory and implications for interaction and collaborative learning in computer conferences. International Journal of Educational Telecommunications, 1(2\&3), 147-166.

Gunawardena, C. N., \& Zittle, F. J. (1997). Social presence as a predictor of satisfaction within a computermediated conferencing environment. American Journal of Distance Education, 11(3), 8-26. https://doi.org/ 10.1080/08923649709526970.

Hara, N., Bonk, C., \& Angeli, C. (2000). Content analysis of online discussion in an applied educational psychology. Instructional Science, 28(2), 115-152.

Harasim, L. (2012). Learning theory and online technologies. Routledge. 
Hassanein, K., \& Head, M. (2007). Manipulating perceived social presence through the web interface and its impact on attitude towards online shopping. International Journal of Human-Computer Studies, 65(8), 689708. https://doi.org/10.1016/j.ijhcs.2006.11.018.

Haythornthwaite, C. (2002). Building social networks via computer networks: creating and sustaining distributed learning communities. In K. Renninger \& W. Shumar (Eds.), Building virtual communities: Learning and change in cyberspace (pp. 159-190). Cambridge University Press.

Hein, D., Mai, C., \& Hußmann, H. (2018). The usage of presence measurements in research: a review. In Proceedings of the International Society for Presence Research Annual Conference (Presence'18). The International Society for Presence Research.

Higgs, M., \& Lichtenstein, S. (2010). Exploring the 'jingle fallacy': a study of personality and values. Journal of General Management, 36(1), 43-61.

Hostetter, C. (2013). Community matters: social presence and learning outcomes. Journal of the Scholarship of Teaching and Learning, 13(1), 77-86.

Hostetter, C., \& Busch, M. (2006). Measuring up online: the relationship between social presence and student learning satisfaction. Journal of Scholarship of Teaching and Learning, 6(2), 1-12.

Jacobson, D. (2001). Presence revisited: imagination, competence, and activity in text-based virtual worlds. Cyberpsychology \& Behavior, 4(6), 653-673.

Johnson, D. W., \& Johnson, R. T. (1989). Cooperation and competition: theory and research. Interaction Book Company.

Johnson, D. W., \& Johnson, R. T. (2009). An educational psychology success story: social interdependence theory and cooperative learning. Educational Research, 38(5), 365-379.

Johnson, D. W., \& Johnson, R. T. (2014). Cooperative learning in 21st century. Anales de Psicología, 30(3), $841-851$.

Johnson, D. W., Johnson, R. T., \& Smith, K. A. (2014). Cooperative learning: improving university instruction by basing practice on validated theory [Special focus issue: Small-group learning in higher educationCooperative, collaborative, problem-based, and team-based learning]. Journal on Excellence in College Teaching, 25(3-4), 85-118.

Jones, C., Dirckinck, L., \& Lindstrom, B. (2006). A relational, indirect, meso-level approach to CSCL design in the next decade. International Journal of Computer-Supported Collaborative Learning, 1(1), 35-56.

Jorge, I. (2010). Social presence and cognitive presence in an online training program for teachers of Portuguese: relation and methodological issues. In Proceedings from IODL and ICEM 2010 joint conference and media days (pp. 427-435).

Jung, I., Choi, S., Lim, C., \& Leem, J. (2002). Effects of different types of interaction on learning achievement, satisfaction and participation in Web-based instruction. Innovations in Education and Teaching International, 39(2), 153-162.

Kang, M., Choi, H., \& Park, S. (2007). Construction and validation of a social presence scale for measuring online learners' involvement. In C. Montgomerie \& J. Seale (Eds.), Proceedings of World Conference on Educational Multimedia, Hypermedia and Telecommunications 2007 (pp. 1829-1833). AACE.

Katz, N., Lazer, D., Arrow, H., \& Contractor, N. (2004). Network theory and small groups. Small Group Research, 35(3), 307-332.

Kear, K. (2010) Social presence in online learning communities. In L. Dirckinck-Holmfeld, V. Hodgson, C. Jones, M. de Laat, D. McConnell, \& T. Ryberg (Eds.), Proceedings of the 7th international conference on networked learning 2010, Aalborg, Denmark.

Kehrwald, B. (2008). Understanding social presence in text-based online learning environments. Distance Education, 29(1), 89-106. https://doi.org/10.1080/01587910802004860.

Kiliç Çakmak, E., Çebi, A., \& Kan, A. (2014). Developing a 'Social Presence Scale' for e-learning environments. Educational Sciences: Theory \& Practice, 14(2), 764-768. https://doi.org/10.12738/estp.2014.2.1847.

Kim, J. (2011). Developing an instrument to measure social presence in distance higher education. British Journal of Educational Technology, 42(5), 763-777. https://doi.org/10.1111/j.1467-8535.2010.01107.x.

Kirschner, P. A. \& Kreijns, K. (2005). Enhancing sociability of computer-supported collaborative learning environments. In R. Bromme, F. Hesse, \& H. Spada (Eds.), Barriers and biases in computer-mediated knowledge communication - and how they may be overcome (pp. 169-191). New York: Springer Science.

Kozan, K., \& Richardson, J. C. (2014). Interrelationships between and among social, teaching, and cognitive presence. The Internet and Higher Education, 21, 68-73. https://doi.org/10.1016/j.iheduc.2013.10.007.

Kreijns, K., \& Kirschner, P. A. (2018). Extending the SIPS-model: A research framework for online collaborative learning. In V. Pammer-Schindler et al (Eds.), Proceedings of the thirteenth European conference on technology enhanced learning (ECTEL 2018) (pp. 277-290) (LNCS 11082). Springer, AG. https://doi.org/ 10.1007/978-3-319-98572-5_21. 
Kreijns, K., Kirschner, P. A., \& Jochems, W. (2002). The sociability of computer-supported collaborative learning environments. Journal of Education Technology \& Society, 5(1), 8-22. Available from: https:// www.jstor.org/stable/jeductechsoci.5.1.8.

Kreijns, K., Kirschner, P. A., Jochems, W., \& van Buuren, H. (2004). Measuring perceived quality of social space in distributed learning groups. Computers in Human Behavior, 20(5), 607-632. https://doi.org/10. 1016/j.chb.2003.11.002.

Kreijns, K., Van Acker, F., Vermeulen, M., \& Van Buuren, H. (2014). Community of Inquiry: Social Presence Revisited. E-Learning and Digital Media, 11(1), 5-18

Kreijns, K., Weidlich, J., \& Rajagopal (2018). The psychometric properties of a preliminary social presence measure using Rasch analysis. In V. Pammer-Schindler et al (Eds.), Proceedings of the thirteenth European conference on technology enhanced learning (ECTEL 2018) (pp. 31-44) (LNCS 11082). Springer, AG. https://doi.org/10.1007/978-3-319-98572-5_3.

Kreijns, K., Bijker,.M., \& Weidlich, J. (2020). A Rasch analysis approach to the development and validation of a social presence measure. In M. S. Khine (Ed.), Rasch measurement: Applications in quantitative educational research (Chapter 11). Springer Singapore. https://doi.org/10.1007/978-981-15-1800-3.

Kreijns, K., Weidlich, J., \& Kirschner, P. A. (2021, in press). Pitfalls of social interaction in online group learning. In Z. Yan (Ed.), Cambridge Handbook of Cyber Behavior. New York: Cambridge University Press.

Larsen, K. R., \& Bong, C. H. (2016). A tool for addressing construct identity in literature reviews and metaanalyses. MIS Quarterly, 40(3), 529-551.

Li, D. (2011). Online social network acceptance: a social perspective. Internet Research, 21(5), 562-580. https:// doi.org/10.1108/10662241111176371.

Lin, G.-Y. (2004). Social presence questionnaire of online collaborative learning: development and validity. Paper presented at the Annual Meeting of the Association for Educational Communications and Technology, Chicago, IL.

Lin, H.-Y., Yeh, Y.-M., \& Chen, W.-C. (2017). Influence of social presence on sense of virtual community. Journal of Knowledge Management, Economics and Information Technology, 7(2), 1-14.

Lombart, M., \& Ditton, T. (1997). At the heart of it all: the concept of presence. Journal of Computer-Mediated Communication, 3(2). https://doi.org/10.1111/j.1083-6101.1997.tb00072.x.

Lowenthal, P. R. (2010). The evolution and influence of social presence theory on online learning. In T. T. Kidd (Ed.), Online education and adult learning: New frontiers for teaching practices (pp. 124-139). : IGI Global.

Lowenthal, P. R., \& Snelson, C. (2017). In search of a better understanding of social presence: an investigation into how researchers define social presence. Distance Education, 38(2), 1-19.

Luria, M., Reig, S., Tan, X. Z., Steinfeld, A., Forlizzi, J., \& Zimmerman, J. (2019). Re-embodiment and coembodiment: exploration of social presence for robots and conversational agents. Paper presented at DIS '19, San Diego, CA, USA. https://doi.org/10.1145/3322276.3322340

Maddrell, J. A. (2011). Community of inquiry Framework and learning outcomes. Unpublished doctoral dissertation. Norfolk, VA: Old Dominion University. https://doi.org/10.25777/zhef-hd28.

McLeod, P. L., Baron, R. S., Marti, M. W., \& Yoon, K. (1997). The eyes have it: minority influence in face-toface and computer-mediated group discussion. The Journal of Applied Psychology, 82(5), 706-718.

Messick, S. (1996). Validity and washback in language testing. Language Testing, 13(3), 241-256.

Moallem, M. (2015). The impact of synchronous and asynchronous communication tools on learner selfregulation, social presence, immediacy, intimacy and satisfaction in collaborative online learning. The Online Journal of Distance Education and e-Learning, 3(3), 55-77.

Molinillo, S., Aguilar-Illescas, R., Anaya-Sánchez, R., \& Vallespín-Arán, M. (2018). Exploring the impacts of interactions, social presence and emotional engagement on active collaborative learning in a social webbased environment. Computers in Education, 123, 41-52.

Moore, M. G., \& Kearsley, G. (1996). Distance education: A systems view. Wadsworth.

Moreno, R., \& Mayer, R. E. (2002). Learning science in virtual reality multimedia environments: role of methods and media. Journal of Education \& Psychology, 94(3), 598-610.

Moreno, R., \& Mayer, R. (2004). Personalized messages that promote science learning in virtual environments. Journal of Education \& Psychology, 96(1), 165-173.

Mykota, D. (2017). The impact of learner characteristics on the multi-dimensional construct of social presence. The Turkish Online Journal of Educational Technology, 16(2), 137-144.

Nysveen, H., Pedersen, P. E., \& Thorbjørnsen, H. (2005). Intention to use mobile services: antecedents and cross service comparisons. Journal of the Academy of Marketing Science, 33(3), 330-347.

Ogara, S. O., Koh, C. E., \& Prybutok, V. R. (2014). Investigating factors affecting social presence and user satisfaction with mobile instant messaging. Computers in Human Behavior, 36, 453-459. https://doi.org/10. 1016/j.chb.2014.03.064. 
Ogonowski, A., Montandon, A., Botha, E., \& Reyneke. (2014). Should new online stores invest in social presence elements? The effect of social presence on initial trust formation. Journal of Retailing and Consumer Services, 21(4), 482-491. https://doi.org/10.1016/j.jretconser.2014.03.004.

Oh, C. S., Bailenson, J. N., \& Welch, G. F. (2018). A systematic review of social presence: definition, antecedents, and implications. Virtual Environments, 5, 1-34. https://doi.org/10.3389/frobt.2018.00114.

Oksanen, K., \& Hämäläinen, R. (2013). Perceived sociability and social presence in a collaborative serious game. International Journal of Game-Based Learning, 3(1), 115-131. https://doi.org/10.4018/ijgbl.2013010103.

Osgood, C. E., Suci, G. J., \& Tannenbaum, P. H. (1957). The measure of meaning. University of Illinois Press.

Öztok, M., \& Kehrwald, B. A. (2017). Social presence reconsidered: moving beyond, going back, or killing social presence. Distance Education, 38(2), 259-266. https://doi.org/10.1080/01587919.2017.1322456.

Palloff, R., \& Pratt, K. (1999). Building learning communities in cyberspace: effective strategies for the online classroom. Jossey-Bass.

Palloff, R., \& Pratt, K. (2005). Collaborating online: Learning together in community. Jossey-Bass.

Picciano, A. G. (2002). Beyond student perceptions: Issues of interaction, presence, and performance in an online course. Journal of Asynchronous Learning Networks, 6(1), 21-40.

Polhemus, L., Shih, L. F., \& Swan, K. (2001). Virtual interactivity: the representation of social presence in an online discussion. Paper presented at the Annual Meeting of the American Educational Research Association, Seattle, WA.

Poth, R. D. (2018). Social presence in online learning. In M. Marmon (Ed.), Enhancing social presence in online environments (pp. 88-116). IGI Global. https://doi.org/10.4018/978-1-5225-3229-3.ch005.

Rasch, G. (1960). Probabilistic models for some intelligence and attainment tests. Danmark Paedagogiske Institut.

Remesal, A., \& Colomina, R. (2013). Social presence and online collaborative small group work: a socioconstructivist account. Computers in Education, 60(1), 357-367. https://doi.org/10.1016/j.compedu. 2012.07.009.

Resta, P., \& Laferriere, T. (2007). Technology in support of collaborative learning. Educational Psychology Review, 19(1), 65-83.

Rettie, R. (2003), Connectedness, awareness and social presence. Paper presented at the 6th Annual International Workshop on Presence, Aalborg: Denmark.

Richardson, J. C., \& Swan, K. (2003). Examining social presence in online courses in relation to students' perceived learning and satisfaction. Journal of Asynchronous Learning Networks, 7(1), 68-88.

Robb, C. A., \& Sutton, J. (2014). The importance of social presence and motivation in distance learning. The Journal of Technology, Management, and Applied Engineering, 30(2).

Rourke, L., \& Anderson, T. (2002). Exploring social communication in asynchronous, text-based computer conferencing. Journal of Interactive Learning Research, 13(3), 259-275.

Rourke, Anderson, Garrison, \& Archer. (2001). Assessing social presence in asynchronous text-based computer conferencing. Journal of Distance Education, 14(2), 50-71.

Rovai, A. P. (2002). Building a sense of community at a distance. International Review of Research in Open and Distance Learning, 3(1), 1-16.

Russo, T. (2000). Social presence: teaching and learning with invisible others, Paper presented at the Second Annual Online Academy Meeting: Creating Effective Online Instruction. University of Kansas.

Russo, T., \& Benson, S. (2005). Learning with invisible others: perceptions of online presence and their relationship to cognitive and affective learning. Educational Technology \& Society, 8(1), 54-62.

Saadatmand, M., Uhlin, L., Hedberg, M., Abjornsson, L., \& Kvarnstrom, M. (2017). Examining learners' interaction in an open online course through the community of inquiry framework. European Journal of Open, Distance and ELearning, 20(1), 61-79.

Sallnäs, E.-L. (2005). Effects of communication mode on social presence, virtual presence, and performance in collaborative virtual environments. Presence, 14(4), 434 449.

Sarason, S. B. (1974). The psychological sense of community: prospects for a community psychology. JosseyBass.

Satar, H. M. (2013). Multimodal language learner interactions via desktop videoconferencing within a framework of social presence: Gaze. ReCALL, 25(1), 122-142. https://doi.org/10.1017/S0958344012000286.

Shin, N. (2003). Transactional presence as a critical predictor of success in distance learning. Distance Education, 24(1), 69-86.

Shin, D.-H. (2013). Defining sociability and social presence in Social TV. Computers in Human Behavior, 29(3), 939-947. https://doi.org/10.1016/j.chb.2012.07.006.

Short, J., Williams, E., \& Christie, B. (1976). The social psychology of telecommunications. Wiley.

Slater, M. (2004). How colorful was your day? Why questionnaires cannot assess presence in virtual environments. Presence Teleoperators and Virtual Environments, 13(4), 484- 493.

Smith, M., \& Kollock, P. (Eds.). (1998). Communities in cyberspace. Routledge. 
So, H.-J., \& Brush, T. A. (2008). Student perceptions of collaborative learning, social presence and satisfaction in a blended learning environment: relationships and critical factors. Computers in Education, 51(1), 318-336.

Song, M., \& Yuan, R. (2015). Beyond social presence: increasing cognitive presence through meaningful interaction. In Proceedings of Global learn Berlin 2015: Global conference on Learning and technology (pp. 731-736). Berlin, Association for the Advancement of Computing in Education (AACE).

Spears, R., Postmes, T., Wolbert, A., Lea, M., \& Rogers, P. (2000). Social psychological influence of ICT on society and their policy implications. Infodrome.

Sung, E., \& Mayer, R. E. (2012). Five facets of social presence in online distance education. Computers in Human Behavior, 28(5), 1738-1747.

Swan, K. P., \& Shih, L. (2005). On the nature and development of social presence in online course discussions. Journal of Asynchronous Learning Networks, 9(3), 115-136.

Tao, Y. (2009). The relationship between motivation and online social presence in an online class (Doctoral dissertation). University of Central Florida.

Thorndike, E. L. (1904). The newest psychology. Education Review, 28, 217-227.

Traver, A. E., Volchok, E., Bidjerano, T., \& Shea, P. (2014). Correlating community college students' perceptions of community of inquiry presences with their completion of blended courses. The Internet and Higher Education, 20, 1-9. https://doi.org/10.1016/j.iheduc.2013.09.001.

$\mathrm{Tu}, \mathrm{C}$. H. (1997). Using CMC to increase the social presence of Chinese students. Paper presented at the Association for Educational Communication and Technology (AECT) annual conference, Albuquerque, NM.

Tu, C. H. (2000). On-line learning migration: from social learning theory to social presence theory in a CMC environment. Journal of Network and Computer Applications, 23(1), 27-37.

Tu, C.-H. (2002a). The measurement of social presence in an online learning environment. International Journal on E-Learning, 1(2), 34-45.

Tu, C.-H. (2002b). The impacts of text-based CMC on online social presence. The Journal of Interactive Online Learning, 1(2), 1-24.

Tu, C. H., \& McIsaac, M. S. (2002). An examination of social presence to increase interaction in online classes. American Journal of Distance Education, 16(2), 131-150.

Vanden Abeele, M., Roe, K., \& Pandelaere, M., (2007). Element validation of the concepts social presence, emotional presence and connectedness and an application of Zajonc's social facilitation theory to social presence research. Paper presented at the 10th Annual International Workshop on Presence, Barcelona, Spain

Veerman, A. (2000). Computer-supported collaborative learning through argumentation. (Doctoral dissertation). Universiteit Utrecht.

Walther, J. B. (1992). Interpersonal effects in computer-mediated interaction: A relational perspective. Communication Research, 19(1), 52-90.

Walther, J. B. (1993). Impression development in computer-mediated interaction. Western Journal of Communication, 57(4), 381-398.

Walther, J. B. (1996). Computer-mediated communication: impersonal, interpersonal, and hyperpersonal interaction. Communication Research, 23(1), 3-43.

Wei, C.-W., Chen, N.-S., \& Kinshuk. (2012). A model for social presence in online classrooms. Educational Technology Research and Development, 60(3), 529-545. https://doi.org/10.1007/s11423-012-9234-9.

Weidlich, J., \& Bastiaens, T. J. (2017). Explaining social presence and the quality of online learning with the SIPS model. Computers in Human Behavior, 72, 479-487.

Weidlich, J., \& Bastiaens, T. J. (2019). Designing sociable online learning environments and enhancing social presence: An affordance enrichment approach. Computers \& Education, 142, 103622.

Weidman, A. C., Steckler, C. M., \& Tracy, J. L. (2017). The jingle and jangle of emotion assessment: imprecise measurement, casual scale usage, and conceptual fuzziness in emotion research. Emotion, 17(2), 267-295.

Whiteside, A. L. (2015). Introducing the social presence model to explore online and blended learning experiences. Online Learning: Official Journal of the Online Learning Consortium, 19(2), 1-20. https:// doi.org/10.24059/olj.v19i2.453.

Whiteside, A. L. (2017). Understanding social presence as a critical literacy. In A. L. Whiteside, A. Garrett Dikkers, \& K. Swan (Eds.), Social presence in online learning: multiple perspectives on practice and research (pp. 133-142). Stylus Publishing.

Whiteside, A. L., \& Garrett Dickers, A. (2016). Leveraging the social presence model: a decade of research on emotion in online and blended learning. In S. Y. Tettegah \& M. P. McGreery (Eds.), Emotions, technology, and learning (pp. 225-241). Elsevier.

Wiener, M., \& Mehrabian, A. (1968). Language within language: Immediacy, a channel in verbal communication. Appleton-Centuray-Crofts. 
Williams, E. A., Duray, R., \& Reddy, V. (2006). Teamwork orientation, group cohesiveness, and student learning: a study of the use of teams in online distance education. Journal of Management Education, 30(4), 592-616. https://doi.org/10.1177/1052562905276740.

Witmer, B. G., \& Singer, M. J. (1998). Measuring presence in virtual environments: A presence questionnaire. Presence: Teleoperators and Virtual Environments, 7, 225-240.

Wright, B. D., \& Masters, G. N. (1982). Rating scale analysis. MESA Press.

Yen, C.-J., \& Tu, C.-H. (2008). Online social presence: a study of score validity of the computer-mediated communication questionnaire. The Quarterly Review of Distance Education, 9(3), 297-310.

Zhao, H., Sullivan, K. P. H., \& Mellenius, I. (2014). Participation, interaction and social presence: an exploratory study of collaboration in online peer review groups. British Journal of Educational Technology, 45(5), 807819.

Publisher's Note Springer Nature remains neutral with regard to jurisdictional claims in published maps and institutional affiliations. 